\title{
Relationship between Diet Quality and Cardiovascular Risk among Middle-Aged West Virginians
}

\author{
Paige Starrett
}

Follow this and additional works at: https://researchrepository.wvu.edu/etd

\section{Recommended Citation}

Starrett, Paige, "Relationship between Diet Quality and Cardiovascular Risk among Middle-Aged West Virginians" (2017). Graduate Theses, Dissertations, and Problem Reports. 6716.

https://researchrepository.wvu.edu/etd/6716

This Thesis is protected by copyright and/or related rights. It has been brought to you by the The Research Repository @ WVU with permission from the rights-holder(s). You are free to use this Thesis in any way that is permitted by the copyright and related rights legislation that applies to your use. For other uses you must obtain permission from the rights-holder(s) directly, unless additional rights are indicated by a Creative Commons license in the record and/ or on the work itself. This Thesis has been accepted for inclusion in WVU Graduate Theses, Dissertations, and Problem Reports collection by an authorized administrator of The Research Repository @ WVU. For more information, please contact researchrepository@mail.wvu.edu. 


\title{
Relationship between Diet Quality and Cardiovascular Risk among Middle-Aged West Virginians
}

\section{Paige Starrett}

Thesis submitted

to the Davis College of Agriculture, Natural Resources \& Design at West Virginia University

in partial fulfillment of the requirements for the degree of

\author{
Master of Science in \\ Nutrition and Food Science \\ Melissa Ventura-Marra, Committee Chairperson \\ Janet Tou \\ Regan Bailey \\ Department of Animal \& Nutritional Sciences \\ Morgantown, West Virginia \\ 2016
}

Keywords: Diet Quality, Cardiovascular Disease Risk, Middle-Aged Adults Copyright 2016 Paige Starrett 


\section{ABSTRACT \\ Relationship between Diet Quality and Cardiovascular Risk among Middle-Aged West Virginians}

\section{Paige Starrett}

\section{Background}

Cardiovascular disease is prevalent in the United States and West Virginians have the highest rates of many CVD risk factors; however, limited research on the relationship between diet quality and risk factors exists in this high risk middle-aged (45-64 years old) population.

\section{Objective}

The objective of this study was to assess the diet quality of middle-aged West Virginians and to determine the associations between diet quality, body mass index, lifestyle factors, health-related quality of life and cardiovascular risk.

\section{Design}

Cross sectional study, convenience sample.

\section{Participants/Setting}

Data were collected from 96 participants aged 45-64 years old residing in North Central West Virginia. Data were obtained from a survey consisting of questions to assess demographic, physical activity, sleep, health-related quality of life, and CVD risk; an in-person data collection session in which anthropometric data, blood pressure and blood for clinical analysis were 
collected; and 3-day 24-hour diet recalls. The diet recalls were conducted within 2-3 weeks of the in-person collection session.

\section{Main Outcome Measures}

Diet quality, measured by the Healthy Eating Index-2010, and CVD risk (10-Year CVD Risk

Calculator and the Life's Simple 7) were assessed. Additional variables that were included are: anthropometry, body composition, physical activity, sleep and health-related quality of life.

\section{Statistical Analysis}

Simple linear and multiple regression models were used to identify the relationships between main outcome measures after adjusting for confounding variables.

\section{Results}

Diet quality was not related to cardiovascular risk based on Life's Simple 7 scores or the 10 -Year CVD Risk Calculator after adjusting for confounding factors. Women had higher diet quality scores and lower CVD risk scores than men. Additionally, older participants had better diet quality than younger participants.

\section{Conclusion}

Better understanding dietary intakes and risk factors of CVD can be used to develop dietary interventions that target increasing fruits and vegetables and reducing high-sodium foods to improve diet quality among middle-aged adults in WV. 


\section{ACKNOWLEDGEMENTS}

There are so many people that have helped me throughout this journey. First and foremost, I would like to thank Dr. Melissa Ventura-Marra for pushing me to reach my full potential and proving me with the guidance to complete my thesis. I would also like to thank my other committee members, Dr. Janet Tou and Dr. Regan Bailey. Dr. Tou, thank you for contributing your time and patience when I know how busy you are. Dr, Bailey, thank you for sharing your knowledge in nutrition research to improve my thesis and manuscript. Thank you Dr. Holaskova for answering all my questions concerning statistics. A big thank you to all of the faculty at the Davis College of Agriculture for helping me in one way or another whether it is turning in yellow sheets or printing out return address labels.

I would like to thank Michelle McGinley, Stephanie Thompson, and Brittany Abruzzino for helping me with my data collection and for their eagerness to help me out whenever possible. Success would not have been possible without them. Thank you to all the individuals who participated in my study. They were so kind to me and an absolute joy to work with.

Thank you Ryan for your encouraging words and positive outlook after stressful days. Thank you to my friends for understanding my absent in this busy time in my life. Lastly, I would like to thank my parents for their constant love and support. Without them I would not have be able to reach this point in my life. 


\section{TABLE OF CONTENTS}

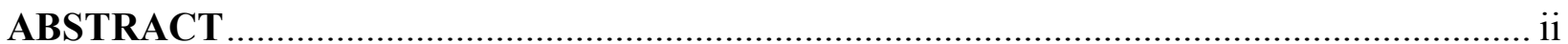

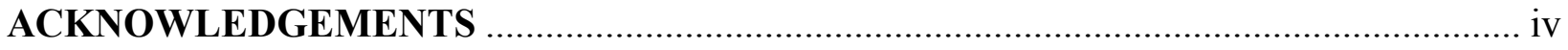

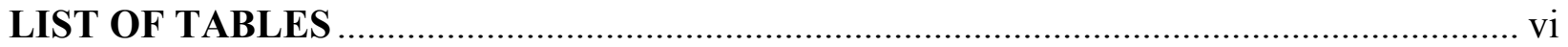

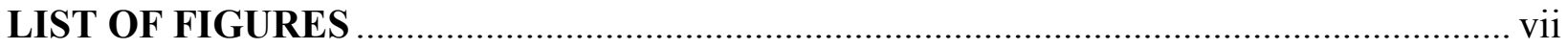

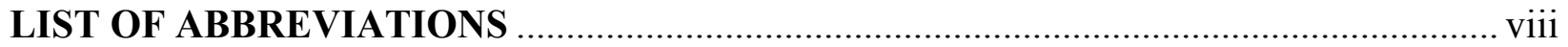

CHAPTER 1: INTRODUCTION

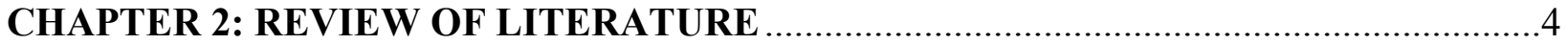

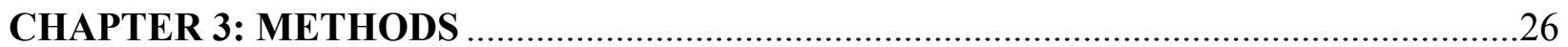

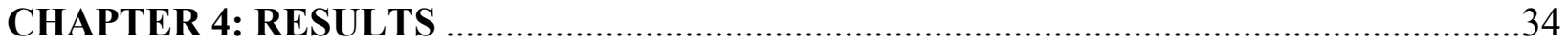

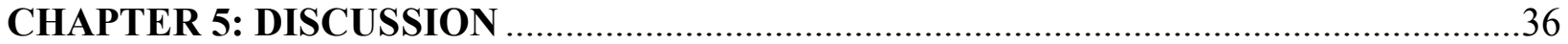

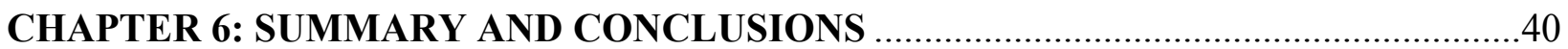

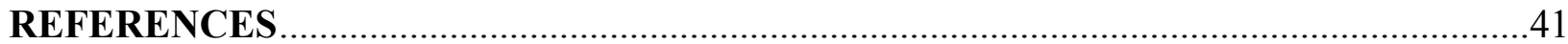




\section{LIST OF TABLES}

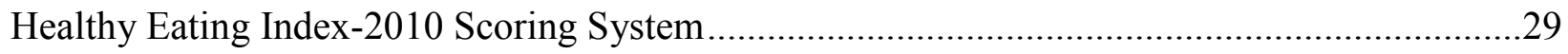

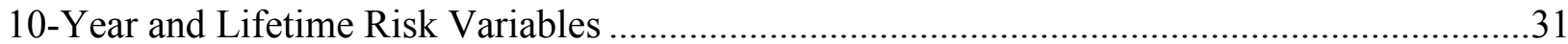

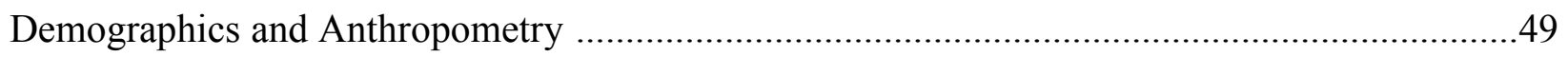

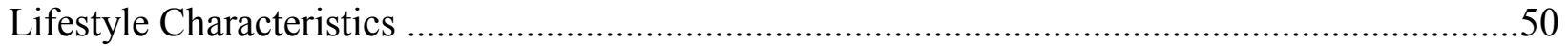

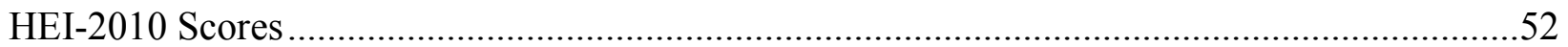

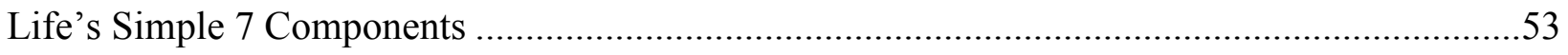

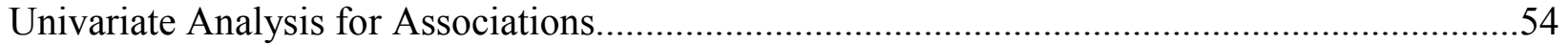

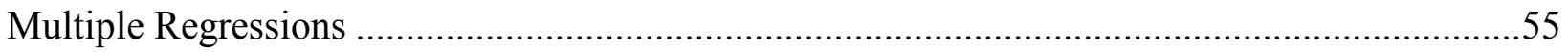




\section{LIST OF FIGURES}

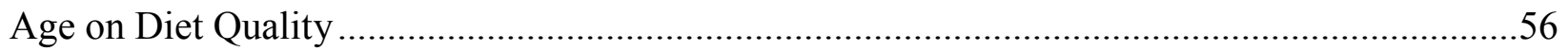

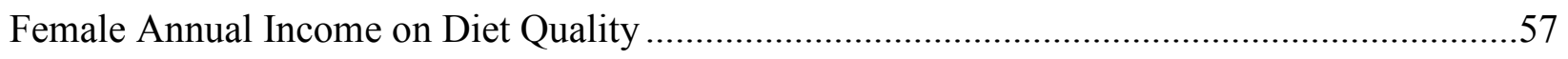

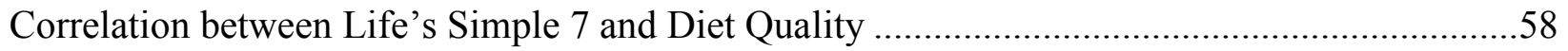

Correlation between Life's Simple 7 and 10-Year Risk.......................................................59 


\section{LIST OF ABBREVIATIONS}

CVD- Cardiovascular Disease

US- United States

AHA- American Heart Association

DGA- Dietary Guidelines for Americans

WV- West Virginia

CHD- Coronary Heart Disease

LS7- Life's Simple 7

BMI- Body Mass Index

ARIC- Atherosclerosis Risk in Communities

NHANES - National Health and Nutrition Examination Survey

BRFSS- Behavioral Risk Factor Surveillance System

ACC-American College of Cardiology

ASCVD- Atherosclerotic Cardiovascular Disease

FRS- Framingham Risk Score

ATPIII- Adult Treatment Panel III

RRS- Reynolds Risk Score

WHS- Women's Health Study

AHEI-2010- Alternative Healthy Eating Index

aMED- Alternative Mediterranean Diet

DASH- Dietary Approach to Stop Hypertension

HR- Hazard Ratio

HEI-2010- The Healthy Eating Index-2010 
HEI-2005- Healthy Eating Index-2005

VAT- Visceral Abdominal Adipose Tissue

SAT- Subcutaneous Abdominal Adipose Tissue

LF- Low Frequency

HF- High Frequency

HELIUS- The Healthy Life in an Urban Setting

IPAQ- The International Physical Activity Questionnaire

HRQOL- Health-Related Quality of Life

MRFIT- Multiple Risk Factor Intervention Trial

CHA- Chicago Heart Association Detection Project in Industry

REDCap- Research Electronic Data Capture

NDSR- Nutrition Data System for Research

HEPA- Health Enhancing Physical Activity

MET- Resting Metabolic Rate

PSQI- Pittsburgh Sleep Quality Index 


\section{CHAPTER 1: INTRODUCTION}

Cardiovascular disease (CVD) is the leading cause of death worldwide with 17.3 million deaths per year. By 2030, the death rate is projected to reach 23.6 million. ${ }^{1}$ Approximately 600,000 deaths in the United States (U.S.) are due to heart disease. ${ }^{2}$ With CVD responsible for such a high mortality rate, a solution to decrease the rate of the disease is imperative. Some lifestyle choices and health conditions are considered risk factors for CVD. The American Heart Association (AHA) developed 2020 Impact Goals for the population stating that by 2020, cardiovascular health will be improved in all Americans by $20 \%$ while reducing deaths from cardiovascular diseases and stroke by $20 \%{ }^{3}$ Ideal cardiovascular health is defined by being a non-smoker, having a body mass index $<25 \mathrm{~kg} / \mathrm{m}^{2}$, meeting physical activity requirements, consuming a diet that adheres to the Dietary Guidelines for Americans (DGA), and having a total cholesterol $<200 \mathrm{mg} / \mathrm{dL}$ achieved without medication, a blood pressure $<120 / 80 \mathrm{~mm} \mathrm{Hg}$ achieved without medication, and a fasting blood glucose $<100 \mathrm{mg} / \mathrm{dL}^{3}{ }^{3}$ The risk for CVD increases with the seriousness of these health factors along with the number that are not present. ${ }^{4}$

West Virginia (WV) has a higher prevalence of CVD risk factors than the national average. In fact, WV has the highest rates of hypertension and diabetes in the nation with $41.0 \%$ and $14.1 \%$ respectively. ${ }^{5}$ Obesity is also prevalent in the state, with more than $35 \%$ of adults being obese in $2014 .{ }^{6}$ When combined with those who are overweight, the number reaches $69.6 \%$ which is higher than the nation average of $64.1 \%{ }^{7}$

Middle-aged adults (45-64 years old) are approaching old age with more CVD risk factors than previous generations. ${ }^{8}$ Middle-aged adults need to implement healthier behaviors early to decrease the rate of CVD and mortality. ${ }^{9}$ In the U.S. middle-aged adults have the highest 
rates of obesity (40.2\%), an important contributor to CVD, when compared to younger adults(39.7.3\%) and older adults(30.8\%). ${ }^{5}$

One of the primary prevention strategies for ideal cardiovascular health is improving diet quality. ${ }^{3}$ The DGA outlines the foods and nutrients important for maintaining good health including cardiovascular health. ${ }^{3,10}$ Increasing consumption of fruits and vegetables decreases the risk of coronary heart disease (CHD).${ }^{11}$ Similarly, consuming higher amounts of whole grains has been associated with lower risk of myocardial infarction. ${ }^{12}$ The DASH diet promotes a diet high in potassium, calcium, magnesium, dietary fiber, protein as well as low in sodium and saturated and trans fats. This diet pattern has been shown to lower blood pressure and LDLcholesterol levels thus reducing CVD risk. ${ }^{13}$ Among middle-aged adults not practicing any healthy lifestyle behaviors, adopting a healthier diet is the most common lifestyle change implemented. ${ }^{9}$

Considering WV has one of the highest rates of risk factors for CVD in the nation, there is a need for immediate intervention. Middle-aged adults had particularly unhealthy behaviors and poorer health conditions compared with other age groups. Suboptimal health in middle-aged adults can lead to many complications individually and state wide. WV has a higher percentage of middle-aged adults than the national average. ${ }^{14,15}$ With a large portion of the population entering old age, WV will encounter an increase in incidences of chronic diseases. Diet quality needs to be assessed to identify the present dietary inadequacies in high risk populations, such as WV. It is important for diet quality, as well as other lifestyle modifications related to CVD, to be examined in middle-aged adults to discover treatments, improve interventions, and develop preventive measures. 
The purpose of this study was to assess the diet quality of middle-aged West Virginians and to determine the associations between diet quality, body mass index, lifestyle factors, healthrelated quality of life and cardiovascular risk in middle-aged adults. 


\section{CHAPTER 2: REVIEW OF LITERATURE}

The primary purpose of this narrative literature review is to investigate what is known about diet quality and cardiovascular health.

\section{Cardiovascular Health}

\section{Life's Simple 7}

Life's Simple 7 (LS7) was developed by the AHA to assess cardiovascular health using 7 components: blood pressure, serum cholesterol, blood sugar, physical activity, diet, body mass index (BMI), and smoking status. ${ }^{3}$ Total scores are classified as either poor, intermediate, or ideal to identify the status of cardiovascular health. Previously, LS7 measures were used to evaluate if lower lifetime risk of heart failure in middle-aged adults (45-64 years old) predicted a greater protection of cardiac structure and function later in life. The Atherosclerosis Risk in Communities (ARIC) collected baseline data from 1987-1989 and final data in 2011-2013 $(n=13,462)$. At the last visit, an echocardiography was performed to identify left ventricular hypertrophy and diastolic dysfunction. Participants with CHD, plaque accumulation in the coronary arteries, at baseline or an incident myocardial infarction during the duration of the study were excluded. ${ }^{16}$ The lifetime risk was $21.3 \%$ through the age of 85 years old. When examining the entire sample, $7 \%$ were categorized as "inadequate," $65 \%$ "average," and 28\% “optimal". Racial differences were seen in the lifetime heart failure risk. Participants who were white had the average lifetime risk of $23.9 \%$ while African Americans had a higher average of 30.6\%. Middle-aged participants who received an optimal score were $40 \%$ less likely than those who received an inadequate score to have the presence of left ventricular hypertrophy. Similarly, middle-aged participants who received an optimal score $(16.2 \%)$ compared to those who received an inadequate score $(27.1 \%)$ were less likely to have diastolic dysfunction. The middle- 
aged participants who had a score of 4 or greater on the ideal health components at baseline had less than one-third the heart failure incidence rate seen in participants who possessed no ideal components. In conclusion, this study found that the LS7 score was significantly inversely associated with incidence and lifetime risk of heart failure. ${ }^{17}$

National Health and Nutrition Examination Survey (NHANES) 2003-2008 data were used to determine the cardiovascular health in U.S. adults $(n=14,515)$. The sample was separated into three age groups; young (20-39 years), middle (40-64 years), and older (65 years and older). In terms of CVD risk, most participants met the ideal smoking status and two-thirds of middle and older aged adults were overweight or obese. Furthermore, the older age group had poorer physical activity levels and fewer women achieved ideal in physical activity. Using the Healthy Diet Score to measure diet quality, the category with the highest adherence was sugar-sweetened beverages and the category with the lowest adherence was sodium and whole grains. Men specifically had better adherence to the fish category, but worse adherence to sodium and fruit and vegetable categories compared to women. Older women had a lower prevalence of ideal blood pressure and total cholesterol, but a higher prevalence of ideal fasting blood glucose compared to men. The proportion of adults reporting treatment for these health conditions increased as age increased. Most middle-aged men had between 2 to 3 ideal cardiovascular health components, while most middle-aged women had approximately 3 ideal components. ${ }^{18}$

Cardiovascular health also varies by state. A study investigating the status of adult's cardiovascular health in each state was conducted using 2009 Behavioral Risk Factor Surveillance System (BRFSS) $(\mathrm{n}=356,441)$. This data was used to supply the LS7 components across the U.S. Only $3.3 \%$ of the total population had ideal cardiovascular health and $9.9 \%$ had poor cardiovascular health with the remaining participants falling somewhere in between. In 
contrast to the study conducted by Shay et al., women reported better cardiovascular health in every category when compared to men. Similar to Shay et al. study, older adults had lower prevalence of ideal cardiovascular health and a higher prevalence of poor cardiovascular health than younger adults. Higher scores were associated with higher educational levels. Only $1.5 \%$ of West Virginians achieved "ideal" on all 7 sections compared to the $6.9 \%$ of those living in the District of Columbia. The lowest mean cardiovascular health score was 4.0 in both WV and Mississippi; the highest mean score was 4.7 in Colorado and the District of Columbia. WV also had the highest percentage $(16.2 \%)$ of individuals in the "poor" cardiovascular health category while Colorado had the lowest ( 6.7\%). ${ }^{19} \mathrm{LS} 7$ is used to compare different populations, but it has also been used to show the progression of cardiovascular health over time.

LS7 has been used to assess cardiovascular health in specific populations. Djoussé et al. examined the progression of CVD risk factors among African Americans using the ideal LS7. The data for this prospective cohort study was collected from 2000 to $2013(n=5,301)$. The percentage of the participants meeting the "ideal" levels for each of the 7 components were: smoking (88.0\%), fasting plasma glucose (45.3\%), cholesterol $(45.2 \%)$, physical activity (19.3\%), blood pressure (17.8\%), BMI (13.7\%), and healthy diet (0.9\%). Diet quality was particularly poor especially when examining sodium and whole grain intake. Fewer components were rated as "ideal" as participants' age increased. The occurrence of "ideal" ratings for serum cholesterol and fasting plasma glucose decreased between visits. This was also true for BMI, but only among participants younger than 40 years of age. Ideal physical activity increased among those older than 40 years of age. No change was observed in ideal blood pressure. ${ }^{20}$ LS7 is a widely used measure of cardiovascular health but other markers of cardiovascular risk have also been developed. 


\section{CVD Risk Calculator}

In 2013, the AHA and the American College of Cardiology (ACC) developed the cardiovascular risk calculator to identify an individual's risk of having a first hard atherosclerotic cardiovascular disease (ASCVD) event (i.e. heart attack or stroke) in the next 10-years based on a risk prediction algorithm. ${ }^{21}$ This tool was developed so that primary care clinicians could recognize a patient that is at risk for CVD and use the results to guide recommendations for lifestyle modifications and statin therapy if the risk exceeds $7.5 \%$ (high risk). Risk scores are calculated based on age, sex, race, total cholesterol, HDL cholesterol, systolic blood pressure, hypertensive medication use, diabetes status, and smoking status. ${ }^{21}$ There are a few differences between LS7 and the CVD risk calculator. LS7 includes actual blood glucose level while the risk calculator asks about diabetes status. The CVD risk calculator takes into account the sex and race of the individual, the LS7 does not. Similar to LS7, the risk calculator includes cholesterol; however, this assessment method doesn't factor in important lifestyle behaviors such as diet, physical activity, or BMI.

There has been some controversy pertaining to the accuracy of the ASCVD risk score. Some studies conclude that the ASCVD risk calculator overestimates CVD risk compared to previous studies. DeFilippis et al. compared the ASCVD risk score with other risk scores including: Framingham Risk Score- Coronary Heart Disease (FRS-CHD), Framingham Risk Score-Cardiovascular Disease (FRS-CVD), Adult Treatment Panel III-Framingham Risk ScoreCoronary Heart Disease (ATPIII-FRS-CHD), and Reynolds Risk Score (RRS) in relation to calibration and discrimination. This multicenter prospective community-based epidemiologic study (MESA) recruited participants aged 45 to 84 years with no clinical diagnosis of CVD from 2000 to 2002 ( $n=4,227)$. To measure the CVD risk score methods, the participants had a follow- 
up after approximately 10 years. The results showed that all methods overestimated cardiovascular events in men: FRS-CHD (53\%), FRS-CVD (37\%), ATPIII-FRS-CHD (154\%), and AHA-ACC-ASCVD (86\%) and women; FRS-CHD (48\%), FRS-CVD (8\%), ATPIII-FRSCHD (46\%), and AHA-ACC-ASCVD (67\%). With the current recommendation of pharmaceutical treatment with a risk score exceeding 7.5\%, examining this precision is essential. Those with ASCVD risk score of $7.5 \%$ to $10 \%$ had a true event rate of $3 \%$ for men and $5.1 \%$ for women. ${ }^{22}$ This discovery is substantial and needs to be noted when using the AHA-ACCASCVD to assess the risk of having a cardiovascular event. This is especially important for doctors who use the tool as guidance for prescribing medication.

A study was conducted to investigate the reason for overestimation and decide if it could be due to the use of statins over time, coronary revascularization procedures, or under reported cardiovascular events. Data were collected from the Women's Health Study (WHS) which included women aged 45-79 who were CVD free $(n=27,542)$. The baseline assessment was conducted form 1992-1995 and the follow up was approximately 10 years later. The average 10year risk score of the population was $3.6 \%$. The $<5 \%$ category encompassed $79 \%$ of women. The average rate predicted was $3.6 \%$ while the true event rate was $2.2 \%$. Continuing the trend of over estimation, those with risk $<7.5 \%$ were given predicted rates $90 \%$ higher than actual rates. Likewise, those with risk $\geq 7.5 \%$ were given predicted rates $40 \%$ higher than actual rates. This would indicate that observed rates after 10 years would need to be $60 \%$ higher compared with the predicted risks that were calculated. Overall, only $1 \%$ of participants had revascularization procedures done. Usage of cholesterol medication increased from approximately $3 \%$ at baseline to $22 \%$ at year 10 . However after calculating for the confounding factors, the average annual proportion using statins would need to be $40 \%$ to explain the overestimation. ${ }^{23}$ According to the 
findings, statin use and revascularization procedures may contribute to the increased risk scores but does not explain the entirety of the inconsistency.

\section{Diet quality and CVD Risk}

Nutrition plays a vital role in preventing and treating chronic conditions, such as CVD. Increasing the consumption of saturated fats and sodium and decreasing the consumption of fruits and vegetables is associated with higher incidences of cardiovascular disease. ${ }^{24}$ The ACC/AHA Lifestyle Management Guideline suggests a diet that higher in vegetables, fruits, and whole grains; moderate intake of low-fat dairy products, poultry, fish, legumes, non-tropical vegetables oils, and nuts; and lower in intake of sweets, sugar-sweetened beverages and red meats. $^{25}$

Georgousopoulou et al. investigated whether of a diet quality measure increases a CVD risk prediction model using data from the ATTICA study. The Mediterranean Diet Score (MedDietScore) was used to assess diet quality and the HellenicSCORE was used to calculate a 10-risk for developing a CVD event. The HellenicSCORE predicts of heart disease risk based on age, gender, smoking habits, systolic blood pressure and total cholesterol. When the MedDietScore was modeled with the HellenicSCORE in analyses, the predicted CVD risk model was improved $(\mathrm{p}<0.001)$. MedDietScore also improved the reclassification rate by $56 \%$. These findings demonstrate the importance of diet quality when predicting CVD risk. ${ }^{26}$ Other studies try to determine if certain components of the diet may be particularly important in predicting future health status.

Hung et al. investigated if fruit and vegetable intake affected incidences of cardiovascular disease and cancer. Females were from the Nurses' Health study $(\mathrm{n}=71,910)$ and men were form the Health Professionals' Follow-up Study $(\mathrm{n}=37,725)$. Two prospective cohorts that were free of 
chronic diseases were given questionnaire that included questions about food frequency, lifestyle choices, and medical history at baseline. Follow-ups were completed to assess any changes in status of chronic diseases and other baseline variables. The results showed that increased fruit and vegetable consumption was inversely correlated to $\mathrm{CVD}(\mathrm{RR}=0.70 ; \mathrm{P}=0.0003) .{ }^{27}$ The strongest inverse relationship was between leafy green vegetables and CVD. ${ }^{27}$ This study showed an association between the consumption of fruit and vegetables with lower incidences of CVD.

Another study examined the influence of changing diet scores on the short-term and longterm risk for CVD in two cohorts: men from the Health Professionals Follow-up Study $(\mathrm{n}=29,343)$ and women from the Nurses' Health Study $(\mathrm{n}=51,195)$. Questionnaires on topics concerning medical history, lifestyle behaviors, and health information were given. Responses were analyzed using the Alternative Healthy Eating Index (AHEI-2010), the Alternative Mediterranean Diet score (aMED), and the Dietary Approach to Stop Hypertension (DASH). After a 4-year period, improvements in diet quality of $11 \%$ to $22 \%$ were shown to lower CVD risk by $7 \%-8 \%$ compared to individuals who make no change to their diet quality. ${ }^{29}$ From baseline to year 4, those who started with the poorest diet quality scores and made the largest improvements had a 15\% lower CVD risk compared to those who had the lowest adherence to diet scores. ${ }^{29}$ This showed that diet quality significantly influences CVD risk.

In a similar study, Reedy et al. researched the relationship between diets, using the following diet assessment methods: Healthy Eating Index-2010 (HEI-2010), AHEI-2010, aMED, and DASH, and all-cause, cardiovascular disease, and cancer mortality. This study used data collected from the NIH-AARP Diet and Health Study, a prospective cohort $(n=492,823)$. Participants were between the ages of 50 and 71 residing in 6 different states. The scores were 
formulated from a 124-item food-frequency questionnaire. There were comparable results across all 4 diet assessment methods. Men and women had a $12 \%$ to $28 \%$ decreased risk of all-cause, CVD, and cancer mortality when comparing those receiving top scores to those receiving low scores. ${ }^{30}$ These findings, similar to the previous study, support that diet quality influences CVD risk.

Multiple lifestyle factors influence CVD, along with diet. Hulsegge et al. conducted a prospective cohort over 5 years, with an 8 to 15 years of follow-up, that investigated the changes in lifestyle factors on CVD and all-cause mortality risk $(\mathrm{n}=5,263)$. Lifestyle factors, including diet, physical activity, cigarette smoking, and alcohol consumption, were self-reported. Diet quality was evaluated from a validated 178-item semi-quantitative food frequency questionnaire. A $57 \%$ to $60 \%$ lower risk of CVD with a hazard ratio (HR) of 0.43 was observed in participants who maintained a healthy lifestyle profile over the 5-year period compared to those who maintained an unhealthy lifestyle. Each healthy lifestyle factor lost from baseline to follow-up increased the risk of CVD to $35 \%$, however it was not significant. ${ }^{31} \mathrm{~A} 48 \%$ lower risk of CVD accompanied the transition from the classification of obesity to the classification of overweight/normal weight compared to remaining obese for an extended period of time. The study results concluded that the factors collected can increase an individual's susceptibility to CVD.

Thomson et al. used the Healthy Eating Index-2005 (HEI-2005) to evaluate the diet quality in the Lower Mississippi Delta region, a high-risk population similar to WV. The diets were collected using a 24-hour diet recall. The results showed differences between demographic groups (sex, race, age, income level, and education level) in the area. The top five dietary sources in each pre-determined food category, accessed from the HEI-2005, were ranked 
differently between these different groups. Among the groups, race and income seem to have less of an effect on dietary choices compared to age. The age of 60 and above had a statistically significant higher score than the younger age groups. ${ }^{32}$ The cross-sectional telephone survey targets the problematic eating habits among the population. The data collected allow for the identification of the greatest contribution of energy across all demographics from the category solid fats, alcoholic beverages and added sugars, as soft drinks. Salty snacks were also seen as a top selection in total and whole grains category which could be the culprit of the high sodium intake $^{32}$. These findings promote a better understanding on how to create cultural messaging for healthier eating in this diverse region.

\section{Measures of Overall Diet Quality}

The DGA is released every five years to advise the public on a healthy diet. The Healthy Eating Index-2010 (HEI-2010) measures the adherence to the DGA by scoring an individual's diet quality from 1-100 (100 indicating completely fulfilling the DGA). Wilson et al. analyzed Americans average diet quality using the HEI-2010 as well as implemented goals for the year 2020. Data based on from the NHANES was collected from the national dietary intake surveillance data in 1999-2000 to 2011-2012. The mean intake for Americans based on the total score was 49 in 1999-2000 and increased to 59 in 2011-2012. This shows that the diet quality is increasing in America; however, if the increasing trend continues, it is not great enough to reach the goal of 74 by $2020 .^{33}$

Demographics could also affect diet quality. Hiza et al. (2013) conducted a study to evaluate the effect of sociodemographic characteristics on diet. The 2003-2004 NHANES was used to collect diet related data to calculate a score using the HEI-2005 in children 2 to 17 years old $(n=3,286)$, young and middle-aged adults 18 to 64 years old $(n=3,690)$, and older adults 65 
years and older $(\mathrm{n}=1,296)$. When comparing adults, participants 75 years and older had the highest total score. Furthermore, participants aged 55 to 64 years had higher total scores compared to the younger adult groups. Higher scores were seen in women compared to men. Adults in the highest income group had higher total scores compared to the lowest income group. The same trend was observed with education. ${ }^{34}$ When addressing the problem of poor diet quality, differences in demographics must be considered.

The cost of food is a barrier to healthy eating that is commonly reported by individuals. Rehm et al. evaluated the relationship between cost (using a national food price database) and diet quality (measured using the HEI-2010). This was a cross sectional analysis of NHANES data from $2007-2008$ and $2009-2010$ for adults over 19 years of age $(n=11,181)$. There is a positive linear association between higher diet quality scores and higher diet cost among all race and ethnicity groups. They also saw a difference in mean scores between men and women. Women tended to have higher diet quality scores than men $(p<0.001)$. Diet quality scores increased with age indicating older adults have diets that adhere better to the DG than younger adults. ${ }^{35}$ These findings illustrate that economic status can pose a restriction on healthy food purchases.

A dietary screening tool for rural older adults was developed to evaluate the diet and overall health of individuals. Bailey et al. developed a tool to assess the nutritional risk in older adults. In a cross-sectional study, 204 older adults were assessed by having an in-person interview as well as biochemical measures taken. Diet recalls were performed using the University of Minnesota's Nutrition Data System for Research software which allows the collection of an individual's diet and dietary supplement information. Two dietary patterns were discovered from the principle component analysis. The first being a "healthy" diet which 
contained fruits, vegetables, lean white meat, dairy, and whole grain products and was negatively associated with fried fish. It was also correlated with increased intakes of niacin, $\beta$-carotene, n-3 fatty acids, fiber, protein, and potassium as well as decreased sodium and fat intake. The second is known as the "western" diet which encompassed sweets and candy, processed meats, and salty snacks and negatively associated with breakfast juices. It was also correlated with increased intakes of added sugars and decreased micronutrients, fiber, and protein. Along with a higher diet quality, the sensible diet was associated with higher HDL cholesterol, lower triglycerides, a smaller waist circumference, and a higher incidence of physical activity. Lower serum vitamin B-12 levels were reported in the Western diet. ${ }^{36}$ This tool gives the advantage of classifying older adults in a risk level in a clinical setting so the appropriate measures can be taken. Older individuals are not the only subgroup that requires a unique dietary screening method to assess their diet.

\section{Risk Factors for CVD}

\section{CVD Risk Factors}

The demographics of a population, sleep quality, physical activity level, and healthrelated quality of life all have been related to CVD. Various factors can have influence diet quality along with age. Healthy lifestyle choices of individuals can dictate health status later in life. King et al. investigated whether implementing healthy lifestyles including, 5 or more fruits and vegetables daily, regular exercise, BMI 18.5-29.9 kg/m2, and smoking status would reduce CVD and mortality. A cohort study was conducted with 45-64 year olds using the Atherosclerosis Risk in Communities survey $(n=15,708)$. After the initial visit, participants were subjected to a follow-up every 3 years for a total of 4 visits. At the first visit, those who had significantly unhealthier lifestyles were 45-54 years, men, African-American, and individuals 
with histories of hypertension or diabetes. Those who had less than college education or family annual incomes less than $\$ 35,000$ were also less more likely to have an unhealthy lifestyle. Of the individuals who adopted a healthy lifestyle, $78 \%$ switched to a healthy diet. Those who were most likely to adopt an overall healthier lifestyle were older, female, with a college education, with family annual incomes greater than $\$ 35,000$, or with no history of hypertension. Those who adopted all 4 healthy lifestyle choices were less likely to have a CVD event $(p<0.001)$ and death $(p=0.009)$ than those who adopted 3 or fewer. After adjusting for demographics, socioeconomic status, and disease history, it was found that over the 4 year period those who lead a healthy lifestyle had a 35\% relative risk reduction of CVD events than those who did not participate in all 4 healthy lifestyle choices. ${ }^{9}$ The chance of a CVD event is associated with an individual's lifestyle choices, but financial circumstances can create a barrier to healthy eating. Obesity

Obesity has been associated with CVD and its risk factors. A study conducted over a 22year period examined the trajectories of change in BMI and other CVD risk factors before a CVD diagnosis. The Rotterdam Study, a prospective population-based study conducted from 1989 to 1993 , recruited individuals over 54 years old and conducted clinical examinations every 4 years $(\mathrm{n}=6,126)$. At the conclusion of the study, 3 distinct BMI trajectories were established; stable weight, progressive weight gain, and progressive weight loss as well as incidence of CVD. The stable weight group had the average BMI of $25.6 \mathrm{~kg} / \mathrm{m}^{2}$. The progressive weight gain group had the mean BMI of $26 . \mathrm{kg} / \mathrm{m}^{2}$ at baseline and then increased to the obesity category ( $\geq 30$ $\mathrm{kg} / \mathrm{m}^{2}$ ) throughout the duration of the study. The progressive weight loss group was in the obesity category at baseline and decreased weight to the normal range throughout the duration of the study. In the CVD-free group, the average BMI remained stable and ranged from 25.0 to 25.9 
$\mathrm{kg} / \mathrm{m} 2$. As for waist circumference, it trajectories followed the same trend as BMI in the progressive weight loss and progressive weight gain groups, but in the stable weight group it was observed that mean waist circumference increased at the follow up visit. In the CVD-free group, the mean waist circumference decreased. The 10-year predicted risk of CVD was also used in this study. The predicted risk increased in all 3 groups at follow-up however the CVD-free group had lower predicted risk compared to all other groups. The prediction risk was significantly higher in the progressive weight gain group compared to the stable weight group. These findings are not sufficient to justify BMI should be used as predictor of CVD. ${ }^{37}$

Waist circumference is also a risk factor for CVD. Data were collected from CVD free participants from the Framingham Heart Study between 2002 and $2005(\mathrm{n}=3,001)$. Visceral abdominal adipose tissue (VAT) and subcutaneous abdominal adipose tissue (SAT) can be a more precise measurement of waist circumference. VAT and SAT were used to identify if there was a correlation with metabolic risk factors such as fasting plasma glucose, total cholesterol, high-density lipoprotein cholesterol, and triglycerides. Metabolic syndrome is a group of risk factors that raises an individual's risk for heart disease which makes it imperative for CVD research. ${ }^{38}$ After adjusting for age, BMI and waist circumference were associated with SAT and VAT measurements. Except for total cholesterol and SAT as well as physical activity and VAT in men, most risk factors were correlated with SAT and VAT. Statistically significant residual effect sizes for VAT were observed for all metabolic risk factors except diabetes in men. Using stepwise linear regression among individuals of normal-weight, overweight, and obese, there was a significant increase in the prevalence of the metabolic syndrome (age-adjusted), BMI, hypertension, and impaired fasting glucose with VAT. These findings suggest that both VAT and SAT are correlated with metabolic risk factors, however VAT was found to be more strongly 
correlated. ${ }^{39}$ These results suggest that waist circumference could be an indicator of CVD and its risk factors.

Sleep

Poor sleep quality can also influence cardiovascular health. The autonomic nervous system includes the sympathetic and parasympathetic mechanisms which balance one another. Low frequency (LF) is associated with both sympathetic and parasympathetic modulation while high frequency (HF) is associated with only parasympathetic modulation. ${ }^{40}$ In a randomized crossover study, 13 healthy men with the mean age of $31 \pm 2$ years old were subjected to a period of regular controlled sleep (7-9.5 hours) and a period of partial sleep deprivation (3.5-5 hours). Dettoni et al. established that partial sleep deprivation increased plasma norepinephrine levels which increases blood pressure. They also observed an increase in LF component of blood pressure variability, and sympathetic modulation of cardiac autonomic balance. Furthermore, sleep deprivation decreased the parasympathetic modulation of cardiac autonomic balance. It was also increased the LF component percent, decreased the HF component percent, and increased the LF-to-HF ratio. After partial sleep deprivation, lower doses of phenylephrine was needed to reach $20 \%$ constriction of the vein $(\mathrm{p}<0.01)$ as well as decreased in maximum venous vasodilatation induced by acetylcholine. ${ }^{41}$ These physiological responses to sleep deprivation could explain the association between poor sleep quality and cardiovascular health.

Sleep deprivation affects many risk factors that contribute to CVD. Anujuo et al. investigated the relationship between sleep deprivation and CVD risk factors such as hypertension, diabetes, obesity and lipid profile. The Healthy Life in an Urban Setting (HELIUS) cohort was comprised of individuals 18-70 years old from several ethnic groups (South Asian Surinamese, African Surinamese, Ghanaians, Turks, Moroccans and the Dutch) residing in the 
Netherlands. Higher rates of obesity are significantly related to sleep duration in the Dutch, South Asian Surinamese, African Surinamese, and Turks ethnic groups $(\mathrm{n}=12,805)$. Sleep deprivation was significantly associated with diabetes in African Surinamese, Turks and Moroccan participants as well as hypertension in Dutch and Turks. In Moroccans, high total cholesterol had a significant positive relationship with sleep deprivation. In South Asian Surinamese, low HDL cholesterol had a positive relationship with sleep deprivation. In South Asian Surinamese, high triglycerides had a positive relationship with sleep deprivation. ${ }^{42}$ Although poor sleep quality affects some ethnic groups differently, it seems it increases risk factors of CVD all the same.

\section{Physical activity and CVD}

The ACC/AHA Lifestyle Management Guideline suggests adults partake in moderate- to vigorous-intensity aerobic physical activity 3 to 4 times per week for an average of 40 minutes of physical activity. In a prospective cohort analysis, female registered nurses 30-55 years old were followed for 8 years to inquire about physical activity and CVD events using questionnaires $(n=72,488)$. Women who were physically active were more likely to be nonsmokers, leaner, had a lower prevalence of reported hypertension, diabetes, and hypercholesterolemia, and had utilized postmenopausal hormone-replacement therapy, multivitamin and vitamin E supplements, and alcohol. Even after controlling for age, smoking status, BMI, and other covariates, the total physical-activity score was inversely related to risk of CVD events when comparing quintile groups with increasing relative risks for physical activity, and the lowest quintile group $(\mathrm{p}=0.002)$. Using multivariate analyses, CVD risk was decreased by $31 \%$ when averaging 4.0 to 6.9 hours per week spent in moderate or vigorous activity as well as $37 \%$ when averaging 7 hours per week compared to those who averaged less than 1 hour per week $(\mathrm{p}<0.001) .{ }^{43}$ Walking 
was also shown to reduce coronary events. Those in the top two quantiles had significantly lower risk for a CVD event compared to those in the lowest quartile. ${ }^{43}$ In women, vigorous activity in addition to walking can reduce CVD events; however this study did not investigate these risks for men.

The Harvard Alumni Health Study investigated physical activity effect of CHD risk in men $(n=12,516)$. Quality and intensity of the physical activity were extracted from questionnaires provided from men with a mean age of age $57.7 \pm 9.0$ years old. Sesso et al. found that total activities and vigorous activities showed a relationship with the risk of CHD. Men who expended $>8400 \mathrm{~kJ}$ per week participating in vigorous activities had a $10 \%$ to $20 \%$ decreased risk of CHD. Men who walked $\geq 5 \mathrm{~km}$ per week had a reduced the risk of CHD by $13 \%$ compared to those who did not. ${ }^{44}$ Similar to women, an increase in physical activity proved a reduced rick for coronary related illnesses.

The International Physical Activity Questionnaire (IPAQ) was used in a study to evaluate novel risk factors and their epidemiological effect on a CVD global risk in a cross-sectional study $(n=1,379)$. The increased CVD risk percentage was correlated with the degree of insulin resistance; the first quartile at $2.71 \%$, the second quartile at $2.73 \%$, the third quartile at $3.48 \%$, and the fourth quartile at $4.52 \%$ which showed significant differences. Higher coronary risk was correlated with higher BMI with $2.23 \%$ in normal weight subjects, $17 \%$ in overweight subjects, and $3.88 \%$ in obese individuals. This trend was also observed for waist circumference. Males with metabolic syndrome had greater risk at 5.66\% than females at $4.61 \%$. The coronary risk was identified for each metabolic syndrome phenotypes; Sick Obese group (3.93\%), Sick Thin subjects (3.90\%), and Sick Overweight subjects (3.55\%). Rojas et al. concluded that these cardiovascular risk factors influenced the coronary risk. ${ }^{45}$ 


\section{Health-Related Quality of Life and CVD}

Health-Related Quality of Life-4 (HRQOL-4) is assessed using a 4 question long questionnaire about general, physical, and mental health. Using the 2003 BRFSS data, adults 18 years and older were evaluated on CVD risk factors including diabetes, hypertension, high cholesterol, obesity, and current smoking status. Li et al. discovered that the percentage of having one of the following: having poor or fair health, 14 or more physically unhealthy days, 14 or more mentally unhealthy days, or 14 or more days of impaired activity, increased along with CVD risk factors for both genders $(\mathrm{p}<0.0001)$ and all three racial/ethnic groups $(\mathrm{p}<0.0001)$. Also the more CVD risk factors present the more likely an individual was to report having poor or fair health $(\mathrm{p}<0.0001) .{ }^{46}$ If an individual already had CVD, they were two- to four times more likely to report lower HRQOL than individuals without CVD. This would conclude that HRQOL deteriorates with CVD and CVD risk factors.

Another study used a 12-month intervention with a health trainer to examine the change CVD risk on HRQOL. Gidlow et al. recruited adults who currently had at least one CVD risk were referred to a health trainer ( $\mathrm{n}=994)$. CVD risk was measured using the Framingham 10-year CVD risk score. It was observed that after the 12-month intervention, there were improvements in CVD risk categories, but there were only small changes seen in clinical measures. Significant reductions in CVD risk were seen in individuals who were high risk at baseline $(\geq 20 \%)$. HRQOL increased from baseline to 12 months in the total sample. There was also positive correlations with the number of times the participant contacted the health trainer and $(\mathrm{p}<.001)$ and the individual's attendance at physical activity facilities $(\mathrm{p}=.004) \cdot{ }^{47} \mathrm{HRQOL}$ is improved by the absence of CVD risk. When healthy lifestyle components are chosen, HRQOL is enhanced.

\section{Middle-Aged Adults and CVD}


Demographic shifts in the proportion of older adults will burdenthe healthcare system. Currently, two out of every three adults that are 65 years or older, have multiple chronic diseases. ${ }^{48}$ The treatment for these adults comprises $66 \%$ of the overall healthcare budget. ${ }^{48}$ The cost of health care for an older adult, that encompasses a significant portion of the population in the near future, costs three to five times the amount it will cost for a younger patient due to the necessary treatment of chronic diseases. ${ }^{48}$ Therefore, if earlier interventions in mid-life adults can prevent chronic diseases in older adults every effort should be made to accomplish this.

CVD risk factors need to be observed in middle-aged population to see if there is an association to increase in mortality from CVD. Stamler et al. evaluated large cohorts from two prospective studies, the Multiple Risk Factor Intervention Trial (MRFIT) and the Chicago Heart Association Detection Project in Industry (CHA) to identify low risk individuals who had serum cholesterol level less than $5.17 \mathrm{mmol} / \mathrm{L}$ ( $<200 \mathrm{mg} / \mathrm{dL}$ ), SBP/DBP of $120 / 80 \mathrm{~mm} \mathrm{Hg}$ or lower, a non-smoker, no history of diabetes or myocardial infarction, and for the 3 CHA cohorts no ECG abnormalities $(\mathrm{n}=366,559)$. Middle-aged men had a lower percentage, $6.0 \%$ (MRFIT) and 4.8\% (CHA), meet the low risk criteria than young adult men, 9.9\% (MRFIT) and 9.4\% (CHA). More middle-aged women had met the low risk category, $6.8 \%(\mathrm{CHA})$ compared to men their age. Middle-aged sub-cohorts had a CHD mortality rate from $77 \%$ to $79 \%$ compared to young adult men sub-cohorts from $86 \%$ to $92 \%$. The middle-aged sub-cohorts at low risk had lower stroke, from $52 \%$ to $76 \%$, and cancer mortalities, from $44 \%$ to $56 \%$ than those not in the low risk category. The middle-aged women low-risk subcohort was $17 \%$ lower for cancer mortality than those not considered low risk. The estimated greater life expectancy for these low-risk subcohorts compared with others was 5.9 for the MRFIT men aged 40-57 years old, 6.0 for the CHA men aged 40- 59 years old, and 5.8 for the CHA women aged 40-59 years old. ${ }^{49}$ 
Preventive measures are needed to reduce the incidence of these risk factors by lower cholesterol and blood pressure and refrain from smoking in the younger generations.

The baby boomer generation refers to the increase in birth rates between 1946 and 1964 . King et al. used NHANES survey data to compare 46-64 year olds in the previous generation (1988-1994) with the baby boomer generation (2007-2010). The purpose being to investigate if one generation was in poorer health than the other. There was a significant difference in excellent health status between baby boomers $(13.2 \%)$ and the previous generation $(32 \%) .{ }^{50}$ This present cohort also required more assistance when walking, more limited in work, and had functional limitations. Baby boomers had higher rates of obesity (38.7\%) compared to the previous generation (29.4\%). They were also less physically active and had a higher percentage of moderate drinking than middle-aged adults in the previous generation. The baby boomer generation had increased rates when it came to certain health conditions such as hypertension, hypercholesterolemia, and diabetes. ${ }^{50}$ This displays that the baby boomer age group are in worse heath compared to previous generation.

With the growing number of older adults, there is a concern of how healthcare will be able to support this group. In a longitudinal cohort study, associations were examined between diet quality and BMI and the health care resource utilization. In rural older adults, Ford et al. found that there was an increased emergency room visits among participants reporting a poor quality diet $(\mathrm{n}=2,995)$. Although there were no associations found between BMI and the health care resource utilization, there was an increase in emergency room visits among individuals in obesity classes II and III. ${ }^{51}$ A preventative measure, for example education on eating healthier, is needed to reduce emergency room visits thereby lessening the burden on the health care system. 
The diets of middle-aged adults are shown to be lacking the appropriate nutrients to achieve optimal health. Not only is healthy eating beneficial for individual health but higher vegetable and fruit consumption are associated with decreased Medicare charges over various years of follow up in middle-aged men. ${ }^{52}$ Thus, diets need to be examined further to determine an appropriate intervention that could yield success.

\section{West Virginia}

In a state where the prevalence of conditions related to CVD are higher than the national average, Marion and Harrison counties are about the middle of the spectrum in regards to CVD and CVD risk factors when examining all 55 counties in WV. When investigating obesity, Harrison County ranks $37^{\text {th }}$ with $32.6 \%$ and Marion County ranks $49^{\text {th }}$ with $29.7 \%{ }^{53}$ As for hypertension, Harrison County ranks 41 with $34.4 \%$ and Marion County ranks $48^{\text {th }}$ with $32.3 \% .{ }^{53}$ When examining CVD, Harrison County ranks $26^{\text {th }}$ with $13.3 \%$ and Marion County ranks $37^{\text {th }}$ with $12 \% .{ }^{53}$ The medium income in these counties is slightly higher than $\mathrm{WV}$ as a whole. West Virginia has a medium household income is $\$ 39,440$ while Harrison County has a medium income of $\$ 40,556$ and Marion County has a medium income of $\$ 39,870 .{ }^{54,55}$ Clarksburg, located in Harrison County, and Fairmont, located in Marion County, are considered Micropolitan Statistical Areas. This means that they have an urban core with at least 10,000 to 50,000 people ${ }^{56,57}$ Rural counties in WV ranked lower in these categories or have either higher or lower medium income could affect diet quality and CVD risk differently than the counties observed here.

When comparing WV and the US, it appears that WV falls short of the national averages in many lifestyle factors that are associated with CVD. For example, nutrition and physical activity are lifestyle choices that influence CVD and that need improvement in WV. Compared 
to the US average, WV consumed fewer than one fruit per day (47.2\% vs. $37.7 \%)$ as well as fewer than one vegetable per day $(26.2 \%$ vs. $22.6 \%) .{ }^{58}$ In addition, WV had less adults meeting the aerobic guideline of at least 150 minutes of aerobic activity per week, (43\% vs $51.6 \%$ ) and a higher percentage not participating in leisure-time physical activity (35.1\% vs $25.4 \%)$ compared to the national average. ${ }^{59}$ Smoking status is another concern; the national median for current smokers, $21.2 \%$, is lower than WV, $28.6 \%{ }^{60}$

\section{Conclusion}

With the population aging and the prevalence of CVD on the rise, the importance of preventative care becomes essential. In a country where healthcare is geared toward treating patients with diseases opposed to a preventative care model, we are now experiencing the repercussions. The decline in the health of middle-aged adults is not only due to the advancement of age, but it is also due to the present population's deterioration of health. Middle-aged adults are a crucial age group to target. They not only can change their own behaviors, but they also possess influence over the younger generation. Identifying the barriers in healthy living and creating an environment for middle-aged adults to be health conscious are the first steps to improving the problems that are becoming inevitable for the healthcare system due to aging. Diet plays a significant part in improving health, whether this is managing existing CVD or preventing new cases. It has become critical to examine the difficulties in a population's diet to help alleviate this problem.

Although some research exists concerning the limitations middle-aged Americans face in terms of diet and consequently health, there is a lack of research in diets of high risk groups, such as the West Virginia. With the distinctive foods and traditions native to West Virginia, generic slogans and messages that are advertised nationally will not be effective. The dietary advice 
needs to be uniquely tailored to this specific region. With West Virginia ranking so high in the key risk factors of CVD as mentioned above, it is important to discover the reasons. Recognizing the major problems in WV that are contributing to CVD is the first step in discovering a solution. Future research in West Virginian's diets and behaviors can help implement a successful intervention to reduce CVD. On a national level, an association between a diet quality and CVD risk would reaffirm the importance of diet and support the current AHA guidelines. 


\section{CHAPTER 3: METHODS}

\section{Study Design}

This was a cross sectional study to assess diet quality and CVD risk among middle-aged adults in an Appalachian population. The study consisted of three components: a 3-day diet assessment, a survey and an in-person data collection session in which anthropometric data, blood pressure and blood for clinical chemical analysis were collected. The survey consisted of demographic questions and validated surveys to assess physical activity, sleep, health-related quality of life, and CVD risk. Participants had the option of taking an online version of the survey or to complete a paper version at the in-person visit. The online version was administered using REDCap (Research Electronic Data Capture) survey software. ${ }^{61}$ In-person sessions were held on six Saturdays between October 2015 and January 2016 at a senior citizens center. Participants received a $\$ 100$ gift card upon completion of the study. The study was approved by West Virginia University’s Institutional Review Board.

\section{Participants}

Participants were recruited from the community by word-of-mouth and community advertising. Additionally, people who participated in previous studies and indicated they would like to be contacted for future studies were invited to participate. To be eligible, participants had to be 45-64 years old, non-smokers, and live in one of the selected two counties in North Central West Virginia. These counties were selected because they represent population areas where prevalence rates of general health, health care coverage, leisure-time physical activity, fruit and vegetable intake, obesity and diabetes are not statistically different than the state average. ${ }^{53}$ Participants were excluded based on the following criteria: if they self-reported having a 
pacemaker or defibrillator, having a diagnosis of cancer or kidney, heart or liver disease, had surgery the previous 6 months, taking anti-inflammatory or anti-coagulant medications, had a major change in diet or appetite in the previous 3 months, abused alcohol or other substances or did not have a telephone.

Demographics

A questionnaire was developed to assess demographic questions such as age, sex, income, education level, alcohol and tobacco use; medication use, and health conditions. Demographic questions were adapted from the CDC's validated BRFSS survey questions. ${ }^{62}$ Anthropometry and Body Composition

Height, weight, waist and hip circumference, and bioelectrical impedance analysis were measured at the in-person visit. All measurements were recorded in duplicate and the average was used for analysis. Height $(\mathrm{cm})$ was measured using the Seca 274 digital mobile stadiometer (Seca, Hamburg, Germany). Weight $(\mathrm{kg})$ and percent body fat was measured using the Seca medical Bioelectrical Composition Analyzer (mBCA) 514 (Seca, Hamburg, Germany). Participants were weighed to the nearest $0.01 \mathrm{~kg}$ wearing light clothing with empty pockets and without shoes. Waist and hip circumferences were measured by the same researcher using a spring-loaded, fiberglass, non-stretchable tape measure (Gulick II Tape Measure, Model 67019; Country Technology, Inc.). Waist circumference $(\mathrm{cm})$ was taken at the iliac crest. ${ }^{63}$ Hip circumference $(\mathrm{cm})$ was measured at the point of maximum protuberance of the buttocks. ${ }^{63}$ Waist-hip ratio was calculated as waist circumference/hip circumference. BMI was calculated body mass index (BMI) as weight $(\mathrm{kg}) /$ height $\left(\mathrm{m}^{2}\right) .{ }^{64}$ BMIs of $18.5-24.9 \mathrm{~kg} / \mathrm{m}^{2}$ were classified as normal, $25.0-29.9 \mathrm{~kg} / \mathrm{m}^{2}$ as overweight, and $30.0-39.9 \mathrm{~kg} / \mathrm{m}^{2}$ as obese. ${ }^{65}$

\section{Diet Quality}


Three 24-hour telephonic dietary recalls were collected by two University of Minnesota trained researchers using the automated four-stage-multiple-pass approach and the Nutrition Data System for Research (NDSR) version 2015 (NDSR version 2012, Nutrition Coordinating Center, University of Minnesota, MN). Recalls were conducted on non-consecutive days within two to three weeks of each participant's in-person data collection session and included one weekend and two weekdays. Diet quality was measured using the HEI-2010. A total score ranging from 0-100 (higher scores indicating greater adherence to the 2010 Dietary Guidelines for Americans) and component scores were determined for each participant based on the average of the three days of intake.

The NDSR output files were transformed into categories and units consistent with the 12 HEI-2010 component constituents (total fruit, whole fruit, vegetables, greens and beans, total grains, refined grains, dairy, total protein foods, seafood and plant proteins, fatty acids, sodium and empty calories). ${ }^{66}$ The HEI-2010 is a density based metric; thus, ratios were determined based on 1,000 calories for each component constituent except fatty acids and empty calories for each of the three days. The mean of the ratios for each of the three day of food intake was calculated and used for analysis. Means ratios for each component were assigned a score. Intakes between the minimum and maximum standards were scored proportionately for each category. Scores for categories were summed to obtain a total score of 0 of 100 . Scores for each category and total scores were used in the analysis. ${ }^{67}$ 
Table 1.

Healthy Eating Index-2010 scoring system used to evaluate diet quality.

\section{Component \\ Maximum Standard for maximum score} score
Standard for minimum score of zero

No fruit

No whole fruit

No vegetables

No dark green vegetables, beans, or peas

No whole grains

No diary

No protein foods

No seafood and plant proteins

(PUFAs +MUFAs)

/ SFAs $<1.2$

$\geq 4.3$ ounce equiv.

$/ 1,000 \mathrm{kcal}$

$\geq 2.0$ grams /

$1,000 \mathrm{kcal}$

$\geq 50 \%$ of energy

\footnotetext{
Adapted from

http://www.cnpp.usda.gov/sites/default/files/healthy_eating_index/CNPPFactSheetNo2.pdf

${ }^{a}$ PUFAs $=$ polyunsaturated fatty acids

${ }^{\mathrm{b}}$ MUFAs $=$ monounsaturated fatty acids

${ }^{\mathrm{c}} \mathrm{SFAs}=$ saturated fatty acids
} 


\section{0-Year and Lifetime Risk of CVD}

Each participants' risk of having a first heart attack or stroke in the next 10-years was estimated using the AHA/ACC risk prediction algorithm. ${ }^{21}$ All participants were between 45 and 64 years of age and self-reported that they did not have existing heart disease, thus it was assumed they had not previously had a heart attack or stroke. In addition, lifetime risk of CVD (the absolute risk percentage compared to a representative population sample) was calculated for 45 to 59 year old participants whose 10 -year risk scores were $<7.5 \%$ (low risk). (See Table 2) Risk scores were calculated based on nine variables: age, sex, race, total cholesterol, HDL cholesterol, systolic blood pressure, hypertensive medication use, diabetes status, and smoking status. $^{21}$ Data for age, sex, race, diabetes status and smoking status were self-reported as part of the demographic survey. Blood pressure was measured at the in-person session using the Omron HEM-907XL Intellisense ${ }^{\circledR}$ Automatic Oscillatory Digital Blood Pressure automatic inflation sphygmomanometer (Omron Health Care, Lake Forest, IL). ${ }^{68}$ The multiple blood pressure measurements were taken by a single researcher. Arm circumference was measured to the nearest $0.1 \mathrm{~cm}$. The measure was used to determine cuff size based on the manufacturer's recommendations. After an initial rest of 5 minutes and using standardized assessment measures, the machine was set to take three blood pressure measurements at 30 -second intervals. ${ }^{69}$ The average reading was used for analysis.

A fasting venous blood draw was performed by a trained phlebotomist at the in-person session. The phlebotomist transported the blood to WVU Hospital laboratory where total and HDL cholesterol were analyzed the same day. 
Table 2 .

The variables needed for calculating the 10-Year and Lifetime Risk and how they were obtained.

\begin{tabular}{|c|c|c|}
\hline Measure & $\begin{array}{l}\text { Study } \\
\text { Component }\end{array}$ & How the measure was obtained \\
\hline Age & $\begin{array}{l}\text { Survey } \\
\text { Demographics }\end{array}$ & What is your age in years? \\
\hline Gender & $\begin{array}{l}\text { Survey } \\
\text { Demographics }\end{array}$ & What is your sex? \\
\hline Race and ethnicity & $\begin{array}{l}\text { Survey } \\
\text { Demographics }\end{array}$ & $\begin{array}{l}\text { Which one or more of the following would you } \\
\text { say is your race? }\end{array}$ \\
\hline Smoking & $\begin{array}{l}\text { Survey } \\
\text { Life's Simple } 7\end{array}$ & $\begin{array}{l}\text { Do you smoke? } \\
\text { Include cigarettes, pipes, and cigars (smoked } \\
\text { tobacco in any form) }\end{array}$ \\
\hline $\begin{array}{l}\text { Treatment for high } \\
\text { blood pressure }\end{array}$ & $\begin{array}{l}\text { Survey } \\
\text { Demographics }\end{array}$ & $\begin{array}{l}\text { Are you taking medication for any of the } \\
\text { following conditions? } \\
\text { - Heartburn or GERD } \\
\text { - High Blood Pressure } \\
\text { - High blood cholesterol } \\
\text { - High blood triglycerides } \\
\text { - } \quad \text { High blood sugar (diabetes or pre-diabetes) } \\
\text { - Weight loss }\end{array}$ \\
\hline Presence of diabetes & $\begin{array}{l}\text { Survey } \\
\text { Life's Simple } 7\end{array}$ & $\begin{array}{l}\text { Do you have diabetes? } \\
\text { (Either type } 1 \text { or type } 2 . \text { ) }\end{array}$ \\
\hline Total cholesterol & $\begin{array}{l}\text { In-person } \\
\text { session }\end{array}$ & Blood draw \\
\hline HDL cholesterol & $\begin{array}{l}\text { In-person } \\
\text { session }\end{array}$ & Blood draw \\
\hline $\begin{array}{l}\text { Systolic blood } \\
\text { pressure }\end{array}$ & $\begin{array}{l}\text { In-person } \\
\text { session }\end{array}$ & Blood pressure measure \\
\hline
\end{tabular}

\section{Life's Simple 7}

Cardiovascular health was determined by calculating each participant's score from the Life's Simple 7 algorithm. ${ }^{3}$ The 11 questions that make up the validated Life's Simple 7 survey were included as part of the study questionnaire. ${ }^{3}$ Additionally, measures from the in-person session were used to assess CVD health based on 7 components: blood pressure, cholesterol, blood sugar, physical activity, diet, weight (BMI), and smoking status. Each variable was 
assigned a score from 0-2 and scores from individual variables are summed to achieve a total score ranging from $0-14$. Total scores were then categorized into a health risk group: inadequate (0-4), average (5-9), optimum (10-14).

\section{Physical Activity, Sleep and Health-Related Quality of Life}

Physical activity was measured using the 7-question IPAQ-short form which measures activity over the past 7 days. ${ }^{70}$ The responses were given a continuous score which is presented as median minutes. Scores were categorized as either Health Enhancing Physical Activity (HEPA), minimally active, or inactive. These categories were based on the following criteria: individuals in the HEPA category participated in vigorous-intensity activity and achieved $\mathrm{a} \geq$ 1500 multiples of the resting metabolic rate (MET) minutes/week on at least 3 days per week or did any combination of walking, moderate-intensity or vigorous intensity activities and achieved a minimum of at least $3000 \mathrm{MET}$-minutes/week on 7 or more days; individuals in the minimally active category participated in 20 minutes of vigorous activity on 3 or more days per week, 30 minutes of moderate-intensity on 5 or more days per week, or achieved a minimum of at least $600 \mathrm{MET}-\mathrm{min} /$ week of any combination of walking, moderate-intensity or vigorous intensity activities on 5 or more days per week; and individuals in the inactive category did not fall into the previous two categories. ${ }^{70}$

Sleep quality was determined using the validated 19-question Pittsburgh Sleep Quality Index (PSQI). Each variable was scored and a global PSQI score (0-21) was determined. ${ }^{71} \mathrm{~A}$ global score of 5 or lower indicates a good sleep quality and a score of 6 or higher indicates poor quality of sleep.

Health-related quality of life was assessed using the validated CDC's HRQOL-4 "Healthy Days Measure". Each question was given a score of 0 or 1 . The 4 questions were then 
summed to give a total score ranging from 0-4 (higher scores indicting, 4 being the worst HRQOL. ${ }^{72-76}$

Data Analysis

All analyses were conducted using JMP version 11 (SAS Institute Inc., Cary, NC). ${ }^{77}$ Descriptive statistics were used for to test for mean differences in demographic characteristics between sexes. Differences in demographic and survey scores were identified using Chi-square for categorical variables and t-tests for continuous variables. If continuous variables were not normally distributed, they were transformed by taking the log of the variable. Simple linear regressions were used to examine the relationships between variables including anthropometrics, HEI-2010 total scores, HEI-2010 component scores, LS7 scores, 10-year risk percentages, and lifetime risk percentages. One-way ANOVA analysis was used to find significance using the demographic variables. Multiple regression analysis was used to identify the relationship between diet quality and the CVD risk adjusting for confounding variables. 


\section{CHAPTER 4: RESULTS}

\section{Participants}

Of the 96 participants, $41(42.7 \%)$ were male and $55(57.3 \%)$ were female and were on average $54.3 \pm 4.6$ years old. Table 3 and 4 shows participant and lifestyle characteristics. Overall, participants were predominately white (97\%), college educated (57\%) and had annual household incomes of 75,000 or more $(46 \%)$. The mean BMI was $30.9 \pm 7.2$ with $23 \%$ of participants were categorized as normal weight, 26\% were overweight and 51\% were obese. Most participants $(30.2 \%)$ were minimally active as evidenced by scores $(2723.7 \pm 2927.6)$. Most $(53.1 \%)$ had poor sleep quality with a mean on the PSQI score of $5.7 \pm 3.4$. Waist circumference was significantly different between men $(108.7 \mathrm{~cm})$ and women $(99.4 \mathrm{~cm})$, but there was no significant difference between obesity rates between men and women.

\section{Diet Quality}

The average HEI-2010 score for this population was $55.5 \pm 14.2$. Table 5 shows HEI total and component scores by sex. The HEI-2010 total mean score was higher for women than men $(58.4 \pm 14.1$ vs $51.5 \pm 13.5 ; P=0.0172)$. Women had significantly higher scores in total fruit $(2.1$ vs $1.2 ; P=0.0051)$, whole fruit ( 2.9 vs $1.8 ; P=0.0056)$, and sodium ( 4.0 vs $2.6 ; P=0.0439)$ than men. Diet quality scores increased with age (See Figure 1). Using One-way ANOVA, higher income was related to a healthier diet in women, but not men $(P=0.0408$ and $P=0.8904)$. Waist circumference and BMI were not related to HEI-2010 scores.

Total fruit $\left(p=0.04 ; r^{2}=0.05\right)$ and whole fruit $\left(p=0.02 ; r^{2}=0.06\right)$ were the only HEI-2010 categories shown to have a significant correlation with cardiovascular health as measure by LS7. Total protein was the only HEI score significantly correlated to the 10-year risk percentage LS7 $(p=0.009)$. No relationship was found between diet quality and the indicators of CVD after 
adjusting for physical activity, sleep, and health-related quality of life.

\section{CVD Risk}

LS7 scores were higher in women when compared to men (9.2 vs 8.5) however, the difference was not significant. None of the participant LS7 scores met the "inadequate" category; $57.3 \%$ were categorized as "average" and $35.4 \%$ as "optimum". The individual components of Life's Simple 7 and the amount of participants who scored in each category can be found in Table 6.

\section{0-Year Risk}

Men had higher 10-year risk percentage than women $(6.6 \pm 3.8$ vs $2.3 \pm 2.4 ; P<0.0001)$, yet both of these means were $<7.5$ which indicates low risk. The same trend was observed for the lifetime risk. Men had a mean risk score of 43.7 and women had a mean risk score of 34.1. LS7 was shown to be significantly correlated to diet quality scores, yet the 10 -year risk score and the lifetime risk score was not (Figure 3). However, there was a significant negative linear correlation between the LS7 and the 10-year risk score; 10-year risk percentage gets lower and the LS7 score improves (Figure 4). Higher waist circumference and waist-to-hip ratios were correlated to higher 10-risk percentages and lower LS7 scores. BMI was related to the 10-year risk percentage, showing that a higher BMI increases an individual's risk for CVD. Those with a high relative fat mass had lower LS7 scores. Better sleep quality and better health-related quality of life, other modifiable lifestyle factors, were related to higher LS7 scores. 


\section{CHAPTER 5: DISCUSSION}

The purpose of this study was to characterize the diet quality and cardiovascular risk in a middle-aged Appalachian population. This study found that diet quality was not related to LS7 or the 10-year risk percentage after adjusting for confounding factors. LS7 scores were related to diet independently, however diet is a component when calculating the score. This is not the case for the 10-year risk percentage. The incorporation of diet quality has been found to make CVD prediction more accurate. ${ }^{78}$ One study found that improving diet quality by $11 \%$ to $22 \%$ can lower CVD risk by $7 \%-8 \%$ compared to individuals who make no change to their diet quality. ${ }^{29}$ A similar study found that men and women had a $12 \%$ to $28 \%$ decreased risk of all-cause, CVD, and cancer mortality when comparing those receiving high scores in diet quality to those receiving low scores. ${ }^{30}$ These findings, similar to the previous study, support that diet quality influences CVD risk. This could be why there was no association found between diet quality and the 10 -year risk percentage.

The accuracy of 10-year risk percentage calculator has been questioned. ${ }^{22,23}$ In one study, it was found that those with ASCVD risk score ranging from $7.5 \%$ to $10 \%$ had an actual event rate of $3 \%$ for men and $5.1 \%$ for women. ${ }^{22}$ Another study investigating the cause of this inconsistency found that the average event rate predicted was 3.6\% whereas the actual event rate was $2.2 \%$. High risk individuals, $\geq 7.5 \%$, had predicted rates $40 \%$ higher than actual event rates while low risk individuals, $<7.5 \%$, were given predicted rates $90 \%$ higher than actual event rates. $^{23}$ The absence of modifiable behaviors such as diet and physical activity when calculating the 10 -year risk percentage could also be related to the lack of precision.

Several reasons could potentially explain the lack of associations seen in this study. First, this was a convenience sample and may not represent the target area as a whole. Those who responded may have had an interest in health and nutrition. The study may have been 
underpowered resulting in a decrease in the capability to identify differences. Also, all measures of health and diet were self-reported. There is potential for bias in self-reporting particularly of diet; for example, people tend to under-estimate their energy intake. ${ }^{79}$

Our study, similar to others in literature, found that WC and WHR were seen to be associated with worse cardiovascular health and higher CVD risk. Visceral abdominal adipose tissue and subcutaneous abdominal adipose tissue have been shown to be correlated with metabolic syndrome risk factors. If waist circumference exceeds $102 \mathrm{~cm}$ for men and $88 \mathrm{~cm}$ for women, an individual is at an increased risk for obesity-related conditions. ${ }^{80}$ A study conducted across 63 countries reported that there was a strong association between WC and CVD. ${ }^{81}$

Previous studies reported that overall women had better diet quality than men. ${ }^{34,35}$ The low consumption of fruits observed could be a factor contributing to the increased CVD risk in WV. A study examining two prospective cohorts saw that increased fruit and vegetable consumption was inversely correlated to $\operatorname{CVD}(\mathrm{P}=0.0003) .{ }^{27}$ This relationship to CVD could be due to the association between the consumption of fruits and vegetables and lower serum cholesterol. ${ }^{28}$ Multiple studies have found that an increase intake of sodium can contribute in the increased incidences in CVD. ${ }^{82,83}$ One study found that increased sodium intake, $>2300 \mathrm{mg} / \mathrm{d}$, was connected to higher CVD risk. ${ }^{84}$ This association is present between sodium and CVD because sodium intake has been shown to increase blood pressure which is a known risk factor for CVD. ${ }^{85,86}$

When comparing average HEI-2010 component scores between this WV population and the U.S., WV scored lower in total fruit, whole fruit, greens and beans, dairy, total protein, seafood and plant proteins, refined grains, and sodium. However, WV scored higher in total vegetables, whole grains, fatty acids, and empty calories. These contributed to WV having a 
worse total average than the U.S. (55.5 vs 59.0). ${ }^{33}$ The HEI-2010 scores could be lower in other areas of WV considering the demographics in the counties observed here compared to other counties. Research in the Lower Mississippi Delta region, another high risk population, found that factors such as race and income seem to have less of an effect on dietary choices compared to age. ${ }^{32}$ Similar to this study, older adults had a better diet quality when compared to younger ages. ${ }^{32,34,35}$ In a study examining at the effect of sociodemographic characteristics on diet, adults in the highest income and education group had enhanced diet quality compared to those in the lowest. ${ }^{34}$

Our study further supports the consistent literature base that women have preferential CVD risk factors when compared to males. It was observed in this study that women had better CVD measures than men. This was also observed in a study comparing CVD risk in the different states in the U.S. using LS7. Using this data, women performed better than men in every category. ${ }^{19}$ Women having better results concerning cardiovascular health is concurrent with this study. In a study studying CVD risk factors and mortality from CVD in a middle-aged population, middle-aged men had a lower percentage meet the low risk criteria than middle-aged women and young adult men. ${ }^{49}$

More middle-aged adults in 2011-2013 reported having poor or fair health compared to middle aged adults in 1997-1999. ${ }^{87}$ With higher rates of obesity and increased rates of health conditions such as hypertension, hypercholesterolemia, and diabetes, middle-aged adults need to make lifestyle changes to improve health. ${ }^{50}$ The increase in these health conditions for middleaged adults will later influence the healthcare system. Considering two out of every three adults that are 65 years or older have multiple chronic diseases and that treatment consists of $66 \%$ of the overall healthcare budget, the situation will inevitably get worse. ${ }^{48}$ Since WV has a high 
percentage of middle-aged adults, interventions with middle-aged adults may be the optimal strategy to reduce risk of chronic disease before this subgroup enters older adulthood. ${ }^{14,15}$ This would improve public health and reduce healthcare expenditures.

\section{Strengths and limitations}

Due to the fact that both CVD score methods included smoking status to calculate the total score and this study only included non-smokers, mean scores were inevitably lower than populations including smokers. Considering the sample in this study had predominately white, high income, and well-educated individuals, the results can't be representative of all of West Virginia. Future studies should research CVD and diet quality on diverse and a larger population in West Virginia.

To our knowledge, there is not another study that compares the relationship between diet quality and new 10-year risk measure. Another strength in this study is the quality of the diet assessment method. Multiple 24-hour recalls collected using the multi-pass method is considered the gold- standard in dietary intake assessment methodology. Diet recalls are commonly used to supply useful dietary information about a population. Multiple diet recalls on weekdays in addition to weekends is ideal when analyzing the diet of a population to form a picture of the usual average intake of a person. Also, the interviewers utilized the USDA's automated multiplepass method which has been shown to be valid when analyzing a population. ${ }^{76}$ Additionally, the diet quality measure used, the HEI-2010, is a systematic metric of diet quality shown to be related to multiple health comes. 


\section{CHAPTER 5: CONCLUSION}

The poor health associated with middle-aged adults needs to be better addressed in health disparate areas such as WV. Diet quality is a modifiable factor that can prevent and manage chronic diseases, such as CVD. Interventions designed to address the specific dietary shortfalls and excess of this target population are needed. Men were found to have poorer diets and higher CVD risk scores than women, thus an intervention focused on increasing fruits and vegetables and decreasing foods high in sodium in this gender group could be a first step to increasing diet quality and improving health in this population. 


\section{References}

1. Heart Disease and Stroke Statistics - At-a-Glance. https://www.heart.org/idc/groups/ahamahpublic/@wcm/@sop/@smd/documents/downloadable/ucm_470704.pdf. Accessed April 3, 2016.

2. Heart Disease Facts \& Statistics | cdc.gov. http://www.cdc.gov/heartdisease/facts.htm. Accessed February 27, 2016.

3. Lloyd-Jones DM, Hong Y, Labarthe D, et al. Defining and Setting National Goals for Cardiovascular Health Promotion and Disease Reduction The American Heart Association's Strategic Impact Goal Through 2020 and Beyond. Circulation. 2010;121(4):586-613. doi:10.1161/CIRCULATIONAHA.109.192703.

4. What Are Coronary Heart Disease Risk Factors? - NHLBI, NIH. https://www.nhlbi.nih.gov/health/health-topics/topics/hd. Published October 23, 2015. Accessed April 3, 2016.

5. West Virginia State Obesity Data, Rates and Trends: The State of Obesity. http://stateofobesity.org/states/wv/. Accessed October 28, 2015.

6. Prevalence of Self-Reported Obesity Among U.S. Adults by State and Territory, BRFSS, 2014. http://www.cdc.gov/obesity/data/table-adults.html. Accessed October 26, 2015.

7. Percent of Adults Who are Overweight or Obese. http://kff.org/other/state-indicator/adultoverweightobesity-rate/. Accessed October 26, 2015.

8. King DE, Matheson E, Chirina S, Shankar A, Broman-Fulks J. The status of baby boomers' health in the united states: The healthiest generation? JAMA Intern Med. 2013;173(5):385386. doi:10.1001/jamainternmed.2013.2006.

9. King DE, Mainous III AG, Geesey ME. Turning Back the Clock: Adopting a Healthy Lifestyle in Middle Age. Am J Med. 2007;120(7):598-603. doi:10.1016/j.amjmed.2006.09.020.

10. Dietary Guidelines - health.gov. http://health.gov/dietaryguidelines/. Accessed May 11, 2016.

11. Dauchet L, Amouyel P, Hercberg S, Dallongeville J. Fruit and Vegetable Consumption and Risk of Coronary Heart Disease: A Meta-Analysis of Cohort Studies. J Nutr. 2006;136(10):2588-2593.

12. Helnæs A, Kyrø C, Andersen I, et al. Intake of whole grains is associated with lower risk of myocardial infarction: the Danish Diet, Cancer and Health Cohort. Am J Clin Nutr. 2016;103(4):999-1007. doi:10.3945/ajen.115.124271. 
13. Obarzanek E, Sacks FM, Vollmer WM, et al. Effects on blood lipids of a blood pressurelowering diet: the Dietary Approaches to Stop Hypertension (DASH) Trial. Am J Clin Nutr. 2001;74(1):80-89.

14. Bureau USC. American FactFinder - Results. http://factfinder.census.gov/faces/tableservices/jsf/pages/productview.xhtml?pid=ACS_14_ 1YR_CP05\&prodType=table. Accessed June 13, 2016.

15. Marion County 2014.pdf.

http://www.dhhr.wv.gov/bhhf/Sections/programs/ProgramsPartnerships/AlcoholismandDru gAbuse/Research/Documents/County\%20Profiles/Marion\%20County\%202014.pdf. Accessed June 13, 2016.

16. What Is Coronary Heart Disease? - NHLBI, NIH. http://www.nhlbi.nih.gov/health/healthtopics/topics/cad. Accessed June 13, 2016.

17. Folsom AR, Shah AM, Lutsey PL, et al. American Heart Association's Life's Simple 7: Avoiding Heart Failure and Preserving Cardiac Structure and Function. Am J Med. 2015;128(9):970-976.e2. doi:10.1016/j.amjmed.2015.03.027.

18. Shay CM, Ning H, Allen NB, et al. Status of cardiovascular health in US adults: prevalence estimates from the National Health and Nutrition Examination Surveys (NHANES) 20032008. Circulation. 2012;125(1):45-56. doi:10.1161/CIRCULATIONAHA.111.035733.

19. Fang J, Yang Q, Hong Y, Loustalot F. Status of cardiovascular health among adult Americans in the 50 States and the District of Columbia, 2009. J Am Heart Assoc. 2012;1(6):e005371. doi:10.1161/JAHA.112.005371.

20. Djoussé L, Petrone AB, Blackshear C, et al. Prevalence and changes over time of ideal cardiovascular health metrics among African-Americans: the Jackson Heart Study. Prev Med. 2015;74:111-116. doi:10.1016/j.ypmed.2015.02.006.

21. Preiss D, Kristensen SL. The new pooled cohort equations risk calculator. Can J Cardiol. 2015;31(5):613-619. doi:10.1016/j.cjca.2015.02.001.

22. DeFilippis AP, Young R, Carrubba CJ, et al. An Analysis of Calibration and Discrimination Among Multiple Cardiovascular Risk Scores in a Modern Multiethnic Cohort. Ann Intern Med. 2015;162(4):266-275. doi:10.7326/M14-1281.

23. Cook NR, Ridker PM. Further insight into the cardiovascular risk calculator: the roles of statins, revascularizations, and underascertainment in the Women's Health Study. JAMA Intern Med. 2014;174(12):1964-1971. doi:10.1001/jamainternmed.2014.5336.

24. Cardiovascular disease risk factors - Diet | World Heart Federation. http://www.worldheart-federation.org/cardiovascular-health/cardiovascular-disease-risk-factors/diet/. Accessed June 14, 2016. 
25. Eckel RH, Jakicic JM, Ard JD, et al. 2013 AHA/ACC Guideline on Lifestyle Management to Reduce Cardiovascular Risk A Report of the American College of Cardiology/American Heart Association Task Force on Practice Guidelines. Circulation. November 2013:01.cir.0000437740.48606.d1. doi:10.1161/01.cir.0000437740.48606.d1.

26. Georgousopoulou EN, Panagiotakos DB, Pitsavos C, Stefanadis C, ATTICA study group. Assessment of diet quality improves the classification ability of cardiovascular risk score in predicting future events: The 10-year follow-up of the ATTICA study (2002-2012). Eur J Prev Cardiol. 2015;22(11):1488-1498. doi:10.1177/2047487314555095.

27. Hung H-C, Joshipura KJ, Jiang R, et al. Fruit and Vegetable Intake and Risk of Major Chronic Disease. J Natl Cancer Inst. 2004;96(21):1577-1584. doi:10.1093/jnci/djh296.

28. Djoussé L, Arnett DK, Coon H, Province MA, Moore LL, Ellison RC. Fruit and vegetable consumption and LDL cholesterol: the National Heart, Lung, and Blood Institute Family Heart Study. Am J Clin Nutr. 2004;79(2):213-217.

29. Sotos-Prieto M, Bhupathiraju SN, Mattei J, et al. Changes in Diet Quality Scores and Risk of Cardiovascular Disease Among US Men and Women. Circulation. 2015;132(23):22122219. doi:10.1161/CIRCULATIONAHA.115.017158.

30. Reedy J, Krebs-Smith SM, Miller PE, et al. Higher diet quality is associated with decreased risk of all-cause, cardiovascular disease, and cancer mortality among older adults. J Nutr. 2014;144(6):881-889. doi:10.3945/jn.113.189407.

31. Hulsegge G, Looman M, Smit HA, Daviglus ML, van der Schouw YT, Verschuren WMM. Lifestyle Changes in Young Adulthood and Middle Age and Risk of Cardiovascular Disease and All-Cause Mortality: The Doetinchem Cohort Study. J Am Heart Assoc. 2016;5(1). doi:10.1161/JAHA.115.002432.

32. Thomson JL, Onufrak SJ, Connell CL, et al. Food and beverage choices contributing to dietary guidelines adherence in the Lower Mississippi Delta. Public Health Nutr. 2011;14(12):2099-2109. doi:10.1017/S1368980011001443.

33. Wilson MM, Reedy J, Krebs-Smith SM. American Diet Quality: Where It Is, Where It Is Heading, and What It Could Be. J Acad Nutr Diet. 2016;116(2):302-310.e1. doi:10.1016/j.jand.2015.09.020.

34. Hiza HAB, Casavale KO, Guenther PM, Davis CA. Diet quality of Americans differs by age, sex, race/ethnicity, income, and education level. J Acad Nutr Diet. 2013;113(2):297306. doi:10.1016/j.jand.2012.08.011.

35. Rehm CD, Monsivais P, Drewnowski A. Relation between diet cost and Healthy Eating Index 2010 scores among adults in the United States 2007-2010. Prev Med. 2015;73:70-75. doi:10.1016/j.ypmed.2015.01.019.

36. Bailey RL, Miller PE, Mitchell DC, et al. Dietary screening tool identifies nutritional risk in older adults. Am J Clin Nutr. 2009;90(1):177-183. doi:10.3945/ajcn.2008.27268. 
37. Dhana K, van Rosmalen J, Vistisen D, et al. Trajectories of body mass index before the diagnosis of cardiovascular disease: a latent class trajectory analysis. Eur J Epidemiol. March 2016. doi:10.1007/s10654-016-0131-0.

38. What Is Metabolic Syndrome? - NHLBI, NIH. http://www.nhlbi.nih.gov/health/healthtopics/topics/ms. Accessed May 15, 2016.

39. Fox CS, Massaro JM, Hoffmann U, et al. Abdominal Visceral and Subcutaneous Adipose Tissue Compartments Association With Metabolic Risk Factors in the Framingham Heart Study. Circulation. 2007;116(1):39-48. doi:10.1161/CIRCULATIONAHA.106.675355.

40. Akselrod S, Gordon D, Ubel FA, Shannon DC, Berger AC, Cohen RJ. Power spectrum analysis of heart rate fluctuation: a quantitative probe of beat-to-beat cardiovascular control. Science. 1981;213(4504):220-222.

41. Dettoni JL, Consolim-Colombo FM, Drager LF, et al. Cardiovascular effects of partial sleep deprivation in healthy volunteers. J Appl Physiol. 2012;113(2):232-236. doi:10.1152/japplphysiol.01604.2011.

42. Anujuo K, Stronks K, Snijder MB, et al. Relationship between short sleep duration and cardiovascular risk factors in a multi-ethnic cohort - the helius study. Sleep Med. 2015;16(12):1482-1488. doi:10.1016/j.sleep.2015.08.014.

43. Manson JE, Hu FB, Rich-Edwards JW, et al. A prospective study of walking as compared with vigorous exercise in the prevention of coronary heart disease in women. $N$ Engl J Med. 1999;341(9):650-658. doi:10.1056/NEJM199908263410904.

44. Sesso HD, Paffenbarger RS, Lee IM. Physical activity and coronary heart disease in men: The Harvard Alumni Health Study. Circulation. 2000;102(9):975-980.

45. Rojas E. Coronary Risk Estimation According to the Framingham-Wilson Score: Epidemiologic Behavior of Innovative Cardio Metabolic Risk Factors in the Maracaibo City. Int J Cardiovasc Res Int J Cardiovasc Res. 2013;2(4).

46. Li C, Ford ES, Mokdad AH, Balluz LS, Brown DW, Giles WH. Clustering of cardiovascular disease risk factors and health-related quality of life among US adults. Value Health J Int Soc Pharmacoeconomics Outcomes Res. 2008;11(4):689-699. doi:10.1111/j.1524-4733.2007.00307.x.

47. Gidlow CJ, Cochrane T, Davey R, et al. One-year cardiovascular risk and quality of life changes in participants of a health trainer service. Perspect Public Health. 2014;134(3):135-144. doi:10.1177/1757913913484419.

48. The State of Aging \& Health in America 2013 state_of_aging_and_health_in_america_2013.pdf. http://www.cdc.gov/features/agingandhealth/state_of_aging_and_health_in_america_2013. pdf. Accessed October 28, 2015. 
49. Stamler J, Stamler R, Neaton JD, et al. Low risk-factor profile and long-term cardiovascular and noncardiovascular mortality and life expectancy: Findings for 5 large cohorts of young adult and middle-aged men and women. JAMA. 1999;282(21):2012-2018.

doi:10.1001/jama.282.21.2012.

50. King DE, Matheson E, Chirina S, Shankar A, Broman-Fulks J. The status of baby boomers' health in the united states: The healthiest generation? JAMA Intern Med. 2013;173(5):385386. doi:10.1001/jamainternmed.2013.2006.

51. Ford DW, Hartman TJ, Still C, et al. Diet quality and body mass index are associated with health care resource use in rural older adults. J Acad Nutr Diet. 2014;114(12):1932-1938. doi:10.1016/j.jand.2014.02.016.

52. Daviglus ML, Liu K, Pirzada A, et al. Relationship of Fruit and Vegetable Consumption in Middle-Aged Men to Medicare Expenditures in Older Age: The Chicago Western Electric Study. J Am Diet Assoc. 2005;105(11):1735-1744. doi:10.1016/j.jada.2005.08.008.

53. BRFSS2013.pdf. http://www.wvdhhr.org/bph/hsc/pubs/brfss/2013/BRFSS2013.pdf. Accessed May 7, 2016.

54. Harrison County 2014.pdf. http://www.dhhr.wv.gov/bhhf/Sections/programs/ProgramsPartnerships/AlcoholismandDru gAbuse/Research/Documents/County\%20Profiles/Harrison\%20County\%202014.pdf. Accessed May 7, 2016.

55. Marion County 2014.pdf.

http:/www.dhhr.wv.gov/bhhf/Sections/programs/ProgramsPartnerships/AlcoholismandDru gAbuse/Research/Documents/County\%20Profiles/Marion\%20County\%202014.pdf. Accessed May 7, 2016.

56. Bulletin 13-01. https://www.whitehouse.gov/sites/default/files/omb/bulletins/2013/b1301.pdf. Accessed May 5, 2016.

57. U. S. Census Bureau DIS. Metropolitan and Micropolitan Statistical Areas Main. http://www.census.gov/population/metro/. Accessed May 7, 2016.

58. State Indicator Report on Fruits and Vegetables, 2013 - State-Indicator-Report-FruitsVegetables-2013.pdf. http://www.cdc.gov/nutrition/downloads/State-Indicator-ReportFruits-Vegetables-2013.pdf. Accessed April 3, 2016.

59. 2014 State Indicator Report on Physical Activity - pa_state_indicator_report_2014.pdf. http://www.cdc.gov/physicalactivity/downloads/pa_state_indicator_report_2014.pdf. Accessed April 3, 2016.

60. Health CO on S and. Smoking and Tobacco Use; Tobacco Control State Highlights 2010; West Virginia; Description of Images. Smoking and Tobacco Use. http:/www.cdc.gov/tobacco/data_statistics/state_data/state_highlights/2010/states/west_vir ginia/longdesc/. Accessed April 3, 2016. 
61. Harris PA, Taylor R, Thielke R, Payne J, Gonzalez N, Conde JG. Research Electronic Data Capture (REDCap) - A metadata-driven methodology and workflow process for providing translational research informatics support. J Biomed Inform. 2009;42(2):377-381. doi:10.1016/j.jbi.2008.08.010.

62. De N, D H, J B, Ca S, Ka M. Reliability and validity of measures from the Behavioral Risk Factor Surveillance System (BRFSS). Soz Praventivmed. 2000;46 Suppl 1:S3-42.

63. Centers for Disease Control and Prevention (CDC). National Center for Health Statistics (NCHS). National Health and Nutrition Examination Laboratory Protocol. 2016. http://www.cdc.gov/nchs/video/nhanes3_anthropometry/circumference/circumference.pdf.

64. National Institutes of Health (NIH). National Institutes of Health (NIH). https://www.nih.gov/. Accessed April 24, 2016.

65. Losing Weight, Body Mass Iindex. http://www.nhlbi.nih.gov/health/educational/lose_wt/BMI/bmi_dis.htm. Accessed June 15, 2016.

66. University of Minnesota NDSR Nutrition Data System For Research. Guide to Creating Variables Needed to Calculate Scores for Each Component of the Healthy Eating Index2010 (HEI-2010). Google Docs. https://drive.google.com/file/d/0B4snm2Q3ffQQTVHUWE1NGNxUnc/view?usp=drive_web\&usp=embed_facebook. Published 2014. Accessed May 2, 2016.

67. Guenther PM, Kirkpatrick SI, Reedy J, et al. The Healthy Eating Index-2010 Is a Valid and Reliable Measure of Diet Quality According to the 2010 Dietary Guidelines for Americans. J Nutr. 2014;144(3):399-407. doi:10.3945/jn.113.183079.

68. Ostchega Y, Nwankwo T, Sorlie PD, Wolz M, Zipf G. Assessing the validity of the Omron HEM-907XL oscillometric blood pressure measurement device in a National Survey environment. J Clin Hypertens Greenwich Conn. 2010;12(1):22-28. doi:10.1111/j.17517176.2009.00199.x.

69. Viera AJ, Zhu S, Hinderliter AL, Shimbo D, Person SD, Jacobs Jr. DR. Diurnal blood pressure pattern and development of prehypertension or hypertension in young adults: the CARDIA study. J Am Soc Hypertens. 2011;5(1):48-55. doi:10.1016/j.jash.2010.12.002.

70. Booth M. Assessment of Physical Activity: An International Perspective. Res $Q$ Exerc Sport. June 2000. http://www.highbeam.com/doc/1G1-64263160.html. Accessed July 30, 2015.

71. Buysse DJ, Reynolds CF, Monk TH, Berman SR, Kupfer DJ. The Pittsburgh Sleep Quality Index: a new instrument for psychiatric practice and research. Psychiatry Res.

1989;28(2):193-213. 
72. Horner-Johnson W, Krahn G, Andresen E, Hall T. Developing Summary Scores of HealthRelated Quality of Life for a Population-Based Survey. Public Health Rep. 2009;124(1):103.

73. Linden W, Yi D, Barroetavena MC, MacKenzie R, Doll R. Development and validation of a psychosocial screening instrument for cancer. Health Qual Life Outcomes. 2005;3:54. doi:10.1186/1477-7525-3-54.

74. Hays RD, Bjorner JB, Revicki DA, Spritzer KL, Cella D. Development of physical and mental health summary scores from the patient-reported outcomes measurement information system (PROMIS) global items. Qual Life Res. 2009;18(7):873-880. doi:10.1007/s11136-009-9496-9.

75. Mielenz T, Jackson E, Currey S, DeVellis R, Callahan LF. Psychometric properties of the Centers for Disease Control and Prevention Health-Related Quality of Life (CDC HRQOL) items in adults with arthritis. Health Qual Life Outcomes. 2006;4:66. doi:10.1186/14777525-4-66.

76. Jiang Y, Hesser JE. Using Item Response Theory to Analyze the Relationship Between Health-Related Quality of Life and Health Risk Factors. Prev Chronic Dis. 2009;6(1). http://www-ncbi-nlm-nih-gov.www.libproxy.wvu.edu/pmc/articles/PMC2644583/. Accessed April 19, 2016.

77. $J M P \circledR$. Cary, NC: SAS Institute Inc; 1989.

78. Georgousopoulou EN, Panagiotakos DB, Pitsavos C, Stefanadis C, ATTICA study group. Assessment of diet quality improves the classification ability of cardiovascular risk score in predicting future events: The 10-year follow-up of the ATTICA study (2002-2012). Eur J Prev Cardiol. 2015;22(11):1488-1498. doi:10.1177/2047487314555095.

79. Jonnalagadda SS, Mitchell DC, Smiciklas-Wright H, et al. Accuracy of energy intake data estimated by a multiple-pass, 24-hour dietary recall technique. J Am Diet Assoc. 2000;100(3):303-308-311.

80. Assessing Your Weight $\mid$ Healthy Weight $\mid$ CDC. http://www.cdc.gov/healthyweight/assessing/. Accessed May 27, 2016.

81. Balkau B, Deanfield JE, Després J-P, et al. International Day for the Evaluation of Abdominal Obesity (IDEA): a study of waist circumference, cardiovascular disease, and diabetes mellitus in 168,000 primary care patients in 63 countries. Circulation. 2007;116(17):1942-1951. doi:10.1161/CIRCULATIONAHA.106.676379.

82. O'Donnell MJ, Yusuf S, Mente A, et al. Urinary sodium and potassium excretion and risk of cardiovascular events. JAMA. 2011;306(20):2229-2238. doi:10.1001/jama.2011.1729.

83. He J, Ogden LG, Vupputuri S, Bazzano LA, Loria C, Whelton PK. DIetary sodium intake and subsequent risk of cardiovascular disease in overweight adults. JAMA. 1999;282(21):2027-2034. doi:10.1001/jama.282.21.2027. 
84. Merino J, Guasch-Ferré M, Martínez-González MA, et al. Is complying with the recommendations of sodium intake beneficial for health in individuals at high cardiovascular risk? Findings from the PREDIMED study. Am J Clin Nutr. 2015;101(3):440-448. doi:10.3945/ajen.114.096750.

85. He FJ, Li J, Macgregor GA. Effect of longer-term modest salt reduction on blood pressure. Cochrane Database Syst Rev. 2013;(4):CD004937. doi:10.1002/14651858.CD004937.pub2.

86. Cardiovascular disease risk factors - Hypertension | World Heart Federation. http://www.world-heart-federation.org/cardiovascular-health/cardiovascular-disease-riskfactors/hypertension/. Accessed June 19, 2016.

87. Case A, Deaton A. Rising morbidity and mortality in midlife among white non-Hispanic Americans in the 21st century. Proc Natl Acad Sci. 2015;112(49):15078-15083. doi:10.1073/pnas. 1518393112. 
Table 3. Demographics and anthropometry in a sample of West Virginians residing in Harrison and Marion counties aged 45-64 years old.

\begin{tabular}{|c|c|c|c|}
\hline & $\begin{array}{c}\text { All } \\
(\mathrm{n}=96)\end{array}$ & $\begin{array}{c}\text { Men } \\
(\mathrm{n}=41)\end{array}$ & $\begin{array}{c}\text { Women } \\
(\mathrm{n}=55)\end{array}$ \\
\hline & $m \epsilon$ & $n \pm$ standard $d t$ & ation $\longrightarrow$ \\
\hline Age, $y$ & $54.3 \pm 4.6$ & $54.2 \pm 4.6$ & $54.4 \pm 4.7$ \\
\hline Height, cm & $169.5 \pm 9.5$ & $178.1 \pm 5.7$ & $6.1 \pm 163.1 *$ \\
\hline Weight, lbs & $196.2 \pm 51.0$ & $221.3 \pm 49.2$ & $177.5 \pm 44.2 *$ \\
\hline Body Mass Index, $\mathrm{kg} / \mathrm{m}^{2}$ & $30.9 \pm 7.2$ & $31.7 \pm 7.8$ & $30.2 \pm 7.3$ \\
\hline Waist Circumference, cm & $103.4 \pm 16.4$ & $108.7 \pm 14.7$ & $99.4 \pm 16.6^{*}$ \\
\hline Waist-to-Hip Ratio, cm & $0.9 \pm 0.1$ & $0.9 \pm 0.07$ & $0.9 \pm 0.06 *$ \\
\hline Relative Fat Mass & $38.4 \pm 8.8$ & $32.4 \pm 6.8$ & $42.9 \pm 7.4^{*}$ \\
\hline \multicolumn{4}{|l|}{ Ethnicity } \\
\hline Hispanic & $1(1.0 \%)$ & $1(2.4 \%)$ & $0(0.0 \%)$ \\
\hline Non-Hispanic & $95(99.0)$ & $40(97.6 \%)$ & $55(100.0 \%)$ \\
\hline \multicolumn{4}{|l|}{ Race } \\
\hline White only & $91(97.0 \%)$ & $36(95.1 \%)$ & $52(98.2 \%)$ \\
\hline Black only & $3(3.0 \%)$ & $2(4.9 \%)$ & $1(1.8 \%)$ \\
\hline More than one race & $2(2.0 \%)$ & $1(2.4 \%)$ & $1(1.8 \%)$ \\
\hline \multicolumn{4}{|l|}{ Income } \\
\hline$<20,000-34,999$ & $10(10.5 \%)$ & $2(5.0 \%)$ & $8(14.5 \%)$ \\
\hline $35,000-49,999$ & $12(13.0 \%)$ & $6(15.0 \%)$ & $6(10.9 \%)$ \\
\hline $50,000-74,999$ & $20(21.0 \%)$ & $8(20.0 \%)$ & $12(21.8 \%)$ \\
\hline 75,000 or more & $44(46.0 \%)$ & $21(52.5 \%)$ & $23(41.8 \%)$ \\
\hline I'd rather not say & $10(10.4 \%)$ & $4(4.2 \%)$ & $6(6.3 \%)$ \\
\hline \multicolumn{4}{|l|}{ Education } \\
\hline Grade 9 through 11 & $1(1.0 \%)$ & $1(2.44 \%)$ & $0(0 \%)$ \\
\hline Grade 12 or GED & $16(17.0 \%)$ & $10(24.4 \%)$ & $6(10.9 \%)$ \\
\hline College 1 year to 3 years & $24(25.0 \%)$ & $8(19.5 \%)$ & $16(29.1 \%)$ \\
\hline College 4 years or more & $55(57.0 \%)$ & $22(53.7 \%)$ & $33(60.0 \%)$ \\
\hline \multicolumn{4}{|l|}{ Body Mass index* } \\
\hline Normal Weight & $22(23.0 \%)$ & $4(9.8 \%)$ & $18(32.7 \%)$ \\
\hline Overweight & $25(26.0 \%)$ & $14(34.2 \%)$ & $11(20.0 \%)$ \\
\hline Obese & $49(51.0 \%)$ & $23(56.1 \%)$ & $26(47.3 \%)$ \\
\hline \multicolumn{4}{|c|}{ Weight-related Health Conditions } \\
\hline High Cholesterol & $46(50.0 \%)$ & $19(51.4 \%)$ & $27(49.1 \%)$ \\
\hline Hypertension & $33(36.0 \%)$ & $12(32.4 \%)$ & $21(38.2 \%)$ \\
\hline High Triglycerides & $26(30.0 \%)$ & $13(37.1 \%)$ & $13(24.5 \%)$ \\
\hline Sleep Apnea & $13(14.0 \%)$ & $8(21.1 \%)$ & $5(9.4 \%)$ \\
\hline Pre-diabetes & $8(9.0 \%)$ & $3(8.6 \%)$ & $5(9.3 \%)$ \\
\hline Diabetes & $6(7.0 \%)$ & $3(7.9 \%)$ & $3(5.7 \%)$ \\
\hline
\end{tabular}

*Significance at $\mathrm{p}<0.05$ 
Table 4. Lifestyle characteristics in 96 of West Virginians residing in Harrison and Marion counties aged 45-64 years old.

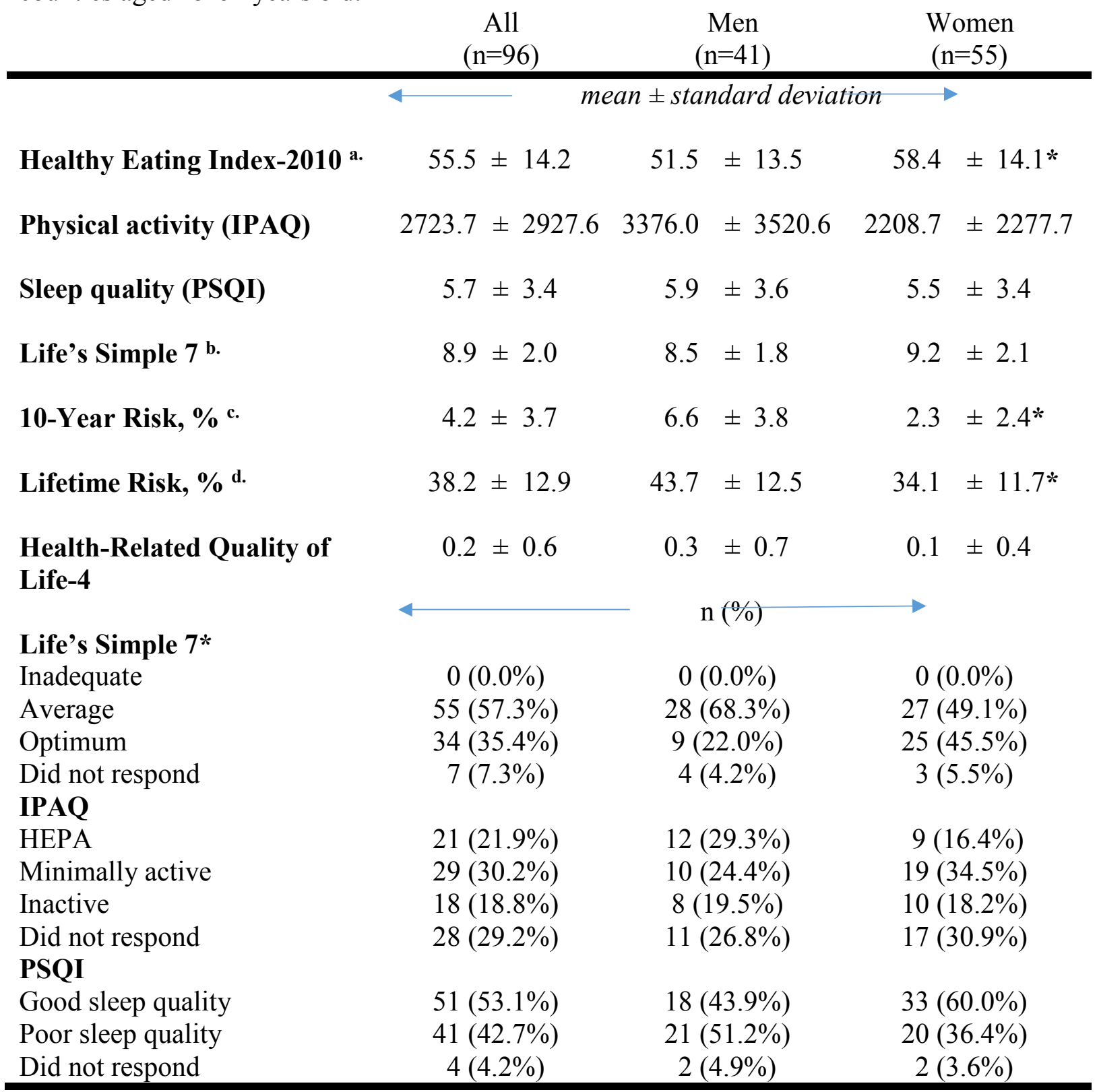

*Significance at $\mathrm{p}<0.05$

a. Scores were calculated by averaging and summing each food category and the energy from each participant's three diet recalls, then dividing the total food category by total energy to achieve ratios. These are converted to component scores which are summed to result in a total score.

b. Scores were calculated by scoring blood pressure, cholesterol, blood sugar, physical activity, diet, weight (BMI), and smoking status scoring independently then summing for a total score. 
c. Scores were calculated from the American Heart Association and the American College of Cardiology risk prediction algorithm from age, sex, race, total cholesterol, HDL cholesterol, systolic blood pressure, hypertensive medication use, diabetes status, and smoking status.

d. Scores were calculated for 45 to 59 year old participants whose 10 -year risk scores were $<7.5 \%$. 


\begin{tabular}{|c|c|c|c|c|c|c|c|c|c|}
\hline \multirow{3}{*}{$\begin{array}{l}\begin{array}{c}\text { Healthy Eating Index- } \\
2010 \text { Component }\end{array} \\
\text { Total fruit }\end{array}$} & \multirow{3}{*}{$\begin{array}{c}\text { Max } \\
\text { score }\end{array}$} & \multicolumn{2}{|c|}{$\begin{array}{c}\text { All } \\
(\mathrm{n}=96)\end{array}$} & \multicolumn{2}{|c|}{$\begin{array}{c}\text { Male } \\
(\mathrm{n}=41)\end{array}$} & \multicolumn{2}{|c|}{$\begin{array}{l}\text { Female } \\
(\mathrm{n}=55)\end{array}$} & \multicolumn{2}{|c|}{$\begin{array}{l}\text { US 2011- } \\
2012^{\mathrm{a} .}\end{array}$} \\
\hline & & 4 & & & ean $(s t$ & indare & error) & & $\rightarrow$ \\
\hline & & 1.7 & $(0.2)$ & 1.2 & $(0.2)$ & 2.1 & $(0.2) *$ & 3.0 & $(0.1)$ \\
\hline Whole fruit & 5 & 2.4 & $(0.2)$ & 1.8 & $(0.3)$ & 2.9 & $(0.3) *$ & 4.0 & $(0.2)$ \\
\hline Total vegetables & 5 & 3.8 & $(0.1)$ & 3.8 & $(0.2)$ & 3.8 & $(0.2)$ & 3.4 & $(0.1)$ \\
\hline Greens and beans & 5 & 2.1 & $(0.2)$ & 1.7 & $(0.3)$ & 2.4 & $(0.3)$ & 3.0 & $(0.1)$ \\
\hline Whole grains & 10 & 4.2 & $(0.3)$ & 4.1 & $(0.5)$ & 4.2 & $(0.5)$ & 2.9 & $(0.1)$ \\
\hline Dairy & 10 & 5.7 & $(0.3)$ & 5.6 & $(0.4)$ & 5.8 & $(0.4)$ & 6.4 & $(0.1)$ \\
\hline Total protein foods & 5 & 4.6 & $(0.1)$ & 4.7 & $(0.1)$ & 4.5 & $(0.2)$ & 5.0 & $(0.0)$ \\
\hline $\begin{array}{l}\text { Seafood and plant } \\
\text { proteins }\end{array}$ & 5 & 2.6 & $(0.2)$ & 2.4 & $(0.3)$ & 2.7 & $(0.3)$ & 3.7 & $(0.2)$ \\
\hline Fatty acids & 10 & 5.1 & $(0.3)$ & 4.7 & $(0.5)$ & 5.4 & $(3.0)$ & 4.7 & $(0.1)$ \\
\hline Refined grains & 10 & 5.1 & $(0.4)$ & 4.8 & $(0.6)$ & 5.4 & $(0.5)$ & 6.2 & $(0.2)$ \\
\hline Sodium & 10 & 3.4 & $(0.3)$ & 2.6 & $(0.4)$ & 4.0 & $(0.4) *$ & 4.2 & $(0.1)$ \\
\hline Empty calories & 20 & 14.9 & $(0.5)$ & 14.3 & $(0.7)$ & 15.4 & $(0.6)$ & 12.6 & $(0.2)$ \\
\hline Total & 100 & 55.5 & (1.5) & 51.5 & (2.1) & 58.4 & $(1.9) *$ & 59.0 & $(0.9)$ \\
\hline
\end{tabular}

*Significance at $\mathrm{p}<0.05$

${ }^{a}$ Wilson MM, Reedy J, Krebs-Smith SM. American Diet Quality: Where It Is, Where It Is Heading, and What It Could Be. J Acad Nutr Diet. 2016;116(2):302-310.e1.

doi:10.1016/j.jand.2015.09.020. 


\begin{tabular}{|c|c|c|c|}
\hline \multicolumn{4}{|c|}{$\begin{array}{l}\text { Table } 6 . \text { Life's Simple } 7 \text { scores in a sample of West Virginians } \\
\text { residing in Harrison and Marion counties } 45-64 \text { years old. }\end{array}$} \\
\hline Blood Pressure & $11(11.0 \%)$ & $\begin{array}{c}n(\%) \\
44(46.0 \%)\end{array}$ & $41(43.0 \%)$ \\
\hline Total Cholesterol & $17(18.0 \%)$ & $53(56.0 \%)$ & $24(26.0 \%)$ \\
\hline Blood sugar & $6(6 \%)$ & $30(32.0 \%)$ & $59(62.0 \%)$ \\
\hline Physical activity & $6(7 \%)$ & $36(40.0 \%)$ & $49(54.0 \%)$ \\
\hline Diet & $32(33.0 \%)$ & $54(56.0 \%)$ & $10(10.0 \%)$ \\
\hline BMI & $49(51.0 \%)$ & $25(26.0 \%)$ & $22(23.0 \%)$ \\
\hline Smoking status & $13(14.0 \%)$ & $13(33 \%)$ & $83(86.0 \%)$ \\
\hline
\end{tabular}


Table 7. Results from univariate analysis for associations with outcomes of diet quality and cardiovascular health in 96 middle-aged adults.

\begin{tabular}{|c|c|c|c|c|c|c|}
\hline \multirow[t]{2}{*}{ Variable } & \multicolumn{2}{|c|}{ HEI-2010 ${ }^{\text {a. }}$} & \multicolumn{2}{|c|}{$10-Y$ ear Risk \% } & \multicolumn{2}{|c|}{$\mathrm{LS} 7^{\mathrm{b}}$} \\
\hline & $r^{2}$ value & Pvalue & $r^{2}$ value & P value & $r^{2}$ value & $P$ value \\
\hline Age & 0.10 & $0.0018 *$ & 0.19 & $0.0001 *$ & 0.05 & $0.0356 *$ \\
\hline $\mathrm{BMI}^{\mathrm{c} .}$ & 0.03 & 0.1121 & 0.11 & $0.0010 *$ & 0.11 & $0.0001 *$ \\
\hline $\mathrm{WC}^{\mathrm{d}}$ & 0.03 & 0.0861 & 0.20 & $0.0001^{*}$ & 0.31 & $0.0001 *$ \\
\hline WHR ${ }^{\text {e. }}$ & 0.02 & 0.1304 & 0.29 & $0.0001^{*}$ & 0.18 & $0.0001 *$ \\
\hline Relative Fat Mass & 0.01 & 0.2968 & 0.03 & 0.0907 & 0.07 & $0.0125 *$ \\
\hline PSQI ${ }^{\mathrm{f}}$ & 0.03 & 0.0811 & 0.008 & 0.4034 & 0.07 & $0.0140 *$ \\
\hline IPAQ $^{g .}$ & 0.001 & 0.7821 & 0.01 & 0.3681 & 0.13 & $0.0030 *$ \\
\hline HRQOL-4 ${ }^{\text {h. }}$ & 0.03 & 0.1413 & 0.02 & 0.2675 & 0.09 & $0.0083 *$ \\
\hline HEI-2010 & N/A & N/A & N/A & N/A & N/A & $\mathrm{N} / \mathrm{A}$ \\
\hline LS7 & 0.04 & $0.0511 *$ & $\mathrm{~N} / \mathrm{A}$ & N/A & N/A & $\mathrm{N} / \mathrm{A}$ \\
\hline $10-Y$ ear Risk \% & 0.002 & 0.7070 & $\mathrm{~N} / \mathrm{A}$ & $\mathrm{N} / \mathrm{A}$ & 0.13 & $0.0004^{*}$ \\
\hline
\end{tabular}

*Significance at $\mathrm{p} \leq 0.05$

${ }^{\text {a }}$ HEI-2010 = Healthy Eating Index-2010

b. LS7=Life's Simple 7

${ }^{\mathrm{c}} \mathrm{BMI}=$ Body Mass Index

${ }^{\mathrm{d}} \mathrm{WC}=$ Waist Circumference

e WHR= Waist-to-Hip Ratio

${ }^{\mathrm{f}} \mathrm{PSQI}=$ Pittsburgh Sleep Quality Index

g IPAQ=International Physical Activity Questionnaire

${ }^{\mathrm{h}}$ HRQOL-4=Health Related Quality of Life-4 


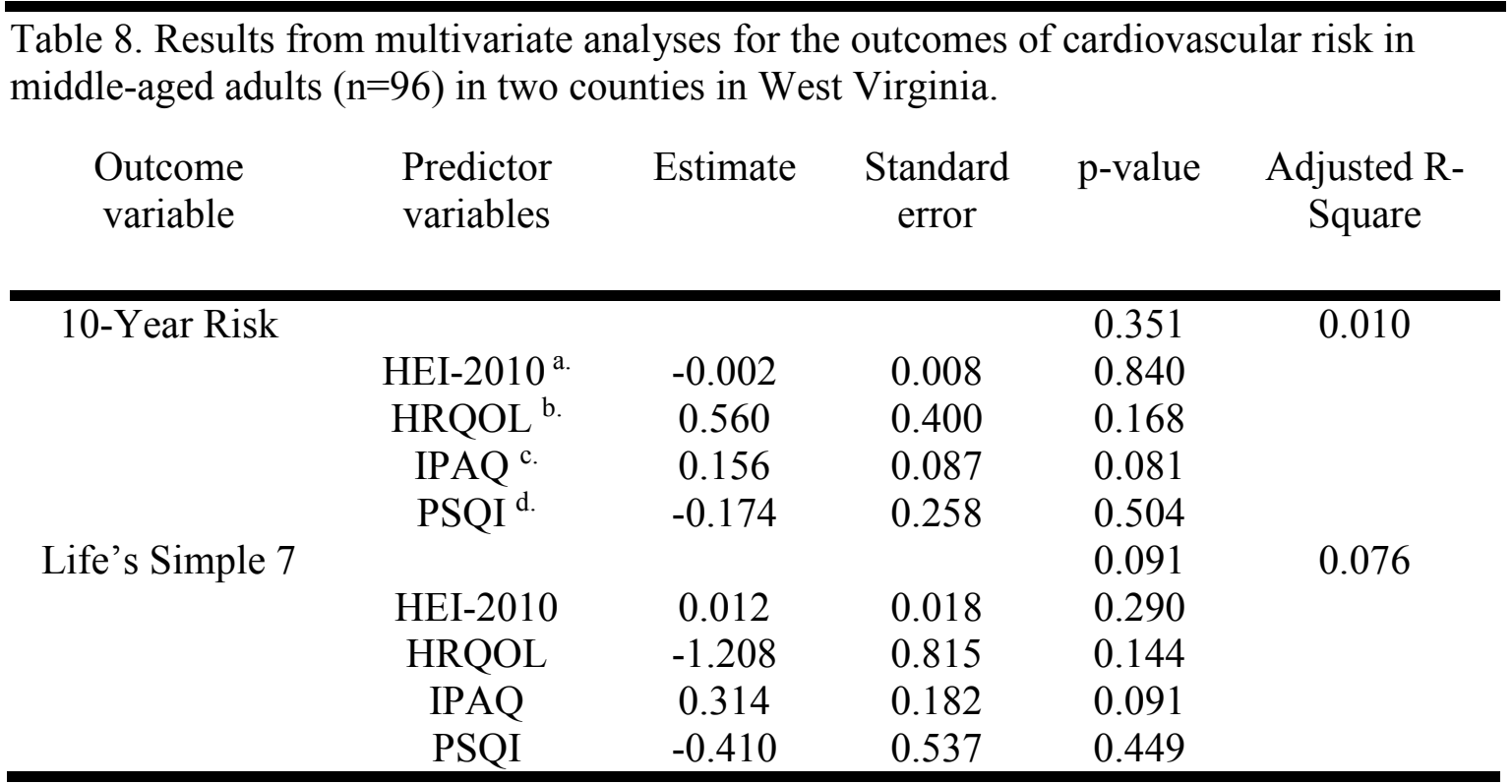

*Significance at $\mathrm{p}<0.05$

${ }^{\text {a } H E I-2010=H e a l t h y ~ E a t i n g ~ I n d e x-2010 ~}$

${ }^{\mathrm{b}}$ HRQOL $=$ Health Related Quality of Life

${ }^{c}$ IPAQ=International Physical Activity Questionnaire

${ }^{\mathrm{d}}$ PSQI=Pittsburgh Sleep Quality Index 
Figure 1. The relationship between age and diet quality, measured by Healthy Eating Index2010.

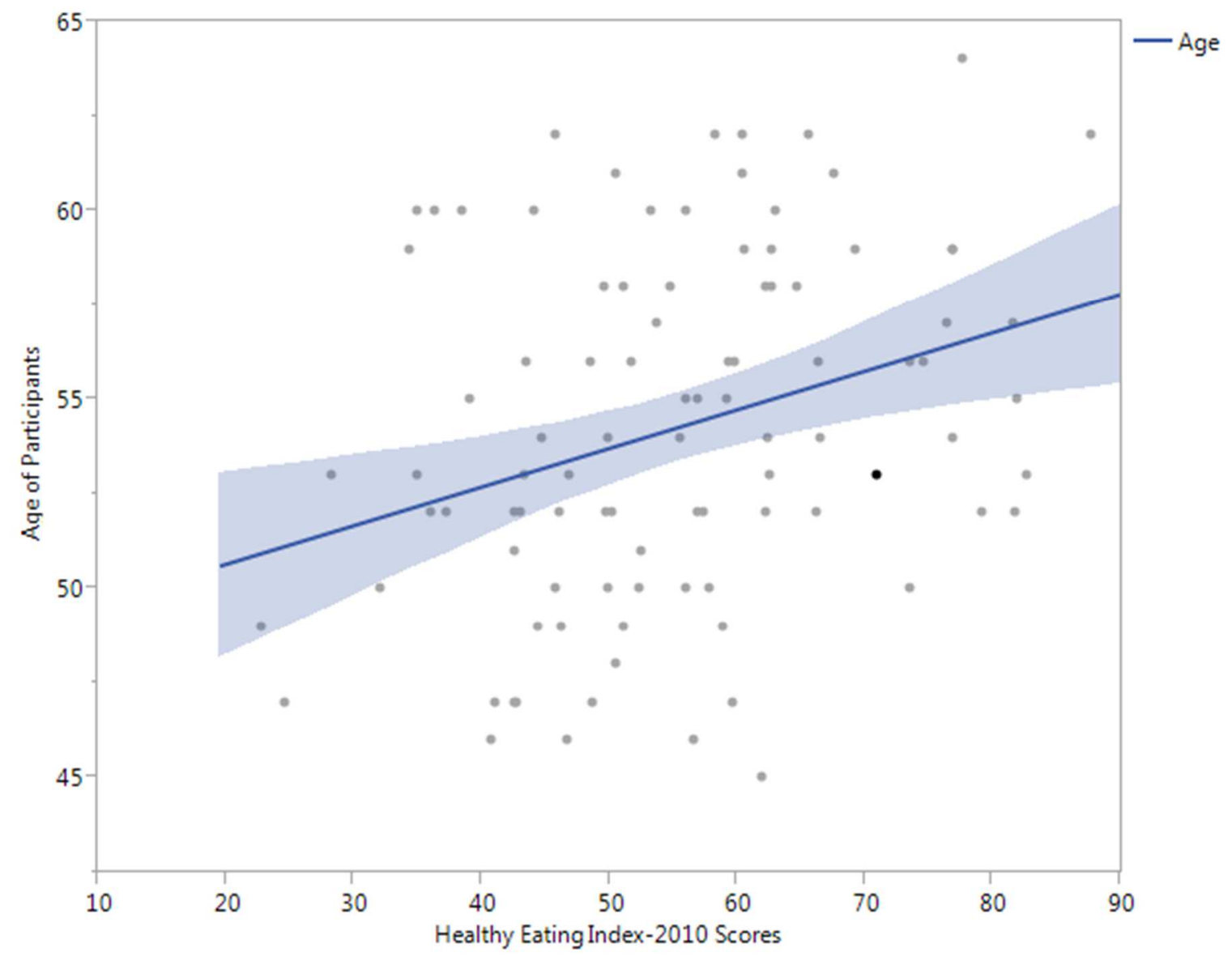


Figure 2. The relationship between annual income reported by females and Healthy Eating Index-2010 scores.

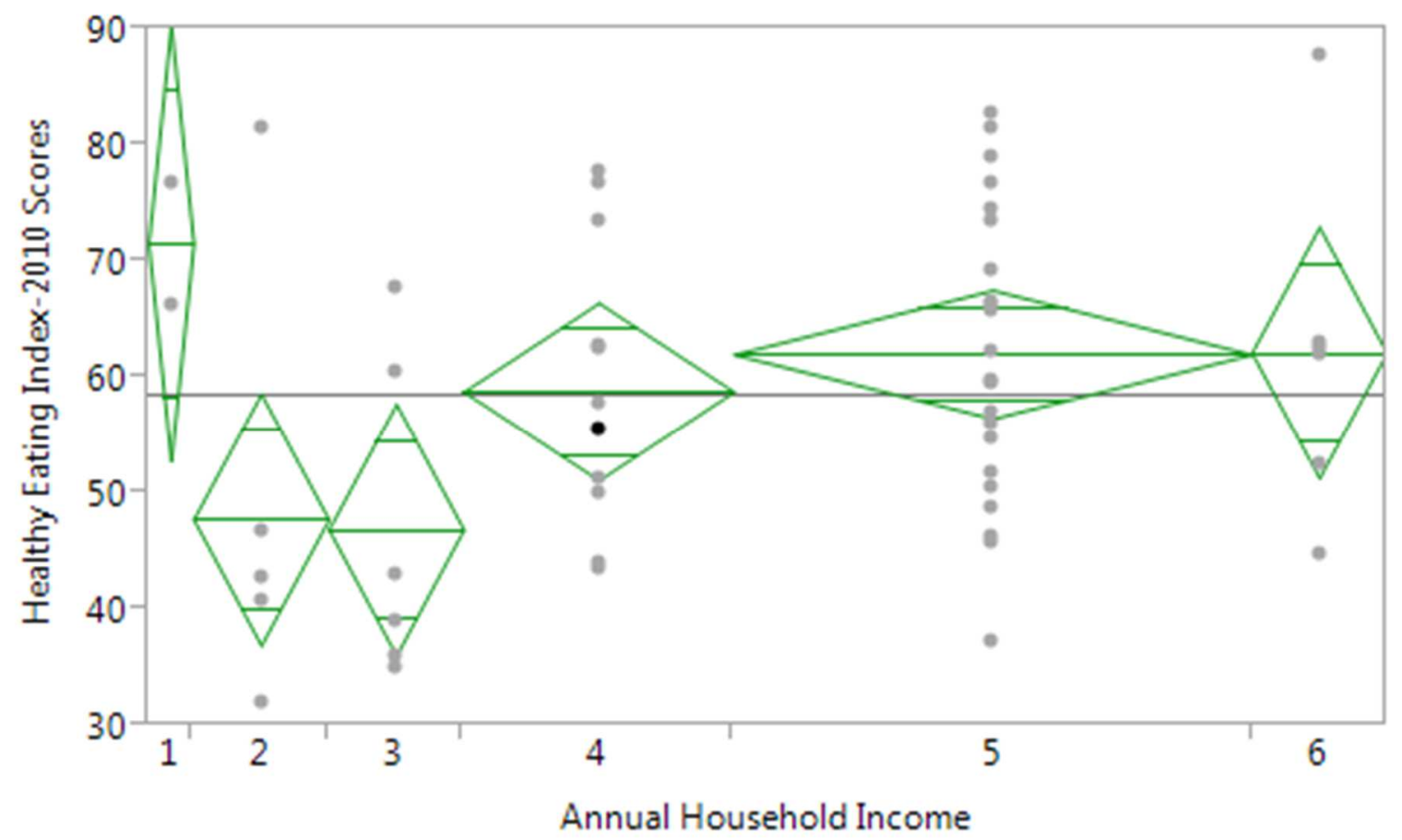


Figure 3. The relationship between diet quality, measured by the Healthy Eating Index-2010 and CVD health, measured by the Life's Simple 7.

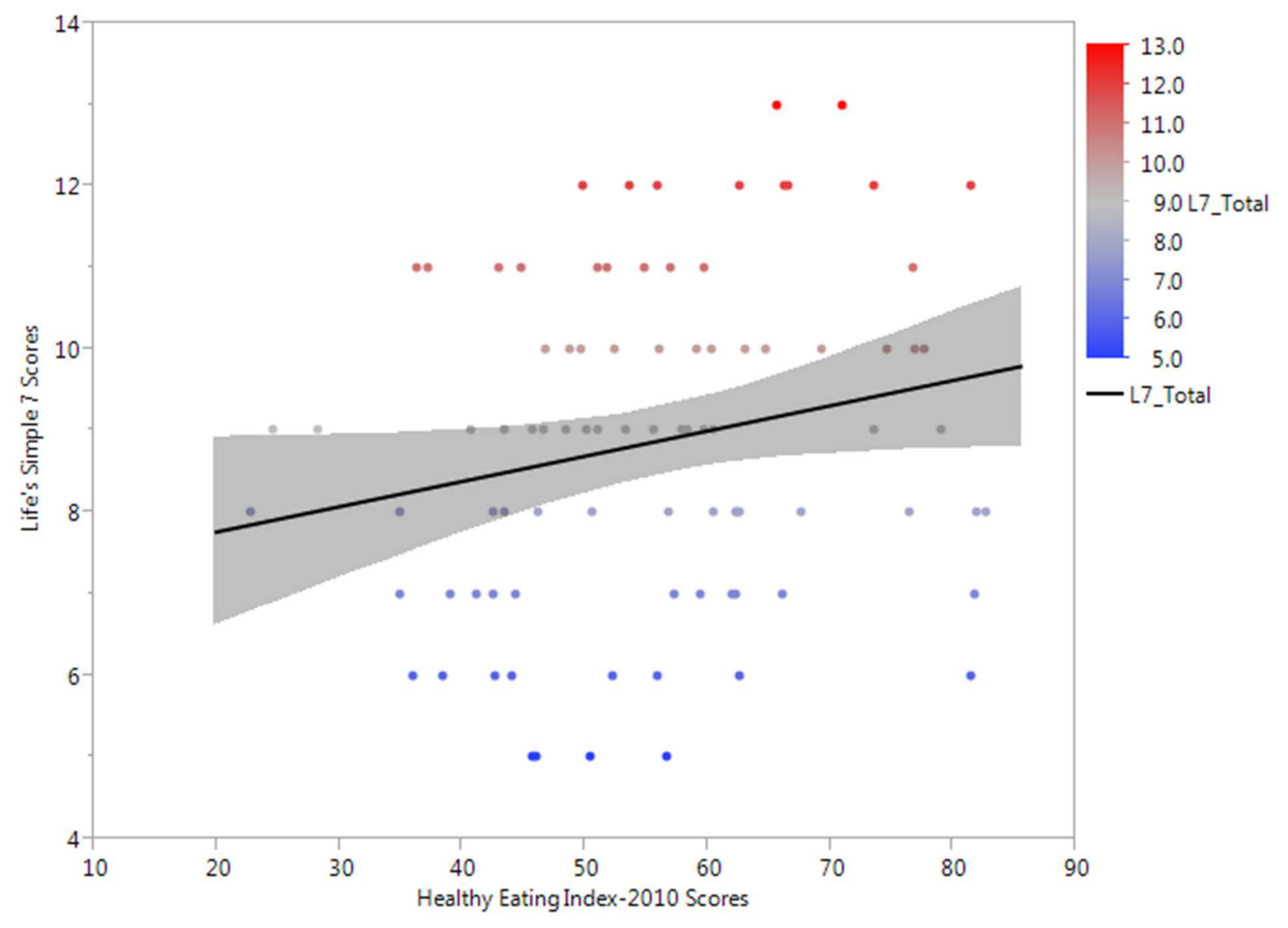


Figure 4. The correlation between Life's Simple 7 score and the 10-Year Risk score.

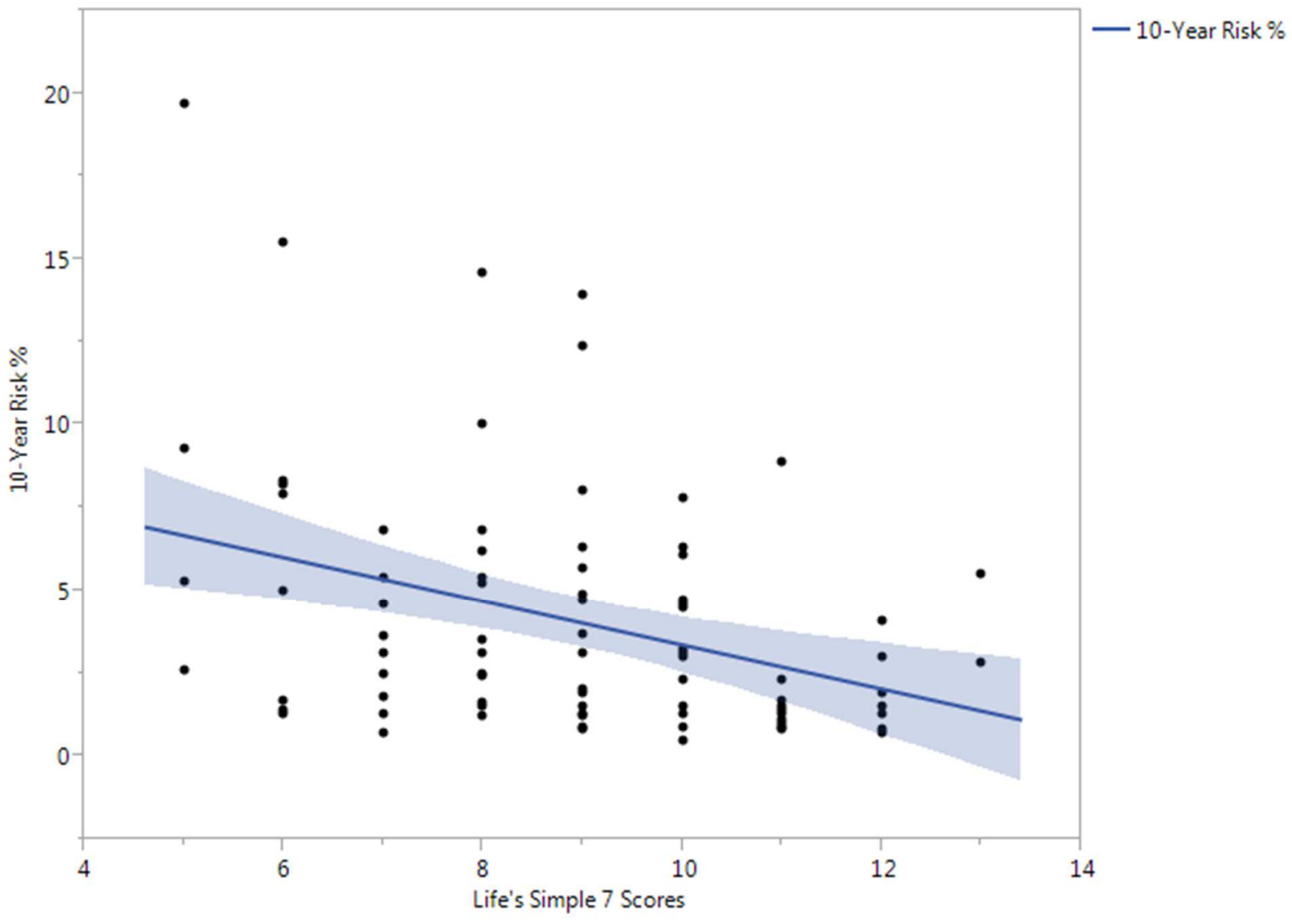

